Andrews University

Digital Commons @ Andrews University

Faculty Publications

$9-1-2020$

\title{
Challenges to Levulinic Acid and Humins Valuation in the Sugarcane Bagasse Biorefinery Concept
}

\author{
Emília Savioli Lopes \\ Universidade Estadual de Campinas \\ Jean Felipe Leal Silva \\ Universidade Estadual de Campinas \\ Elmer Ccopa Rivera \\ Andrews University, ccoparivera@andrews.edu \\ Alana Petrina Gomes \\ Universidade Federal de Sao Paulo \\ Melina Savioli Lopes \\ Universidade Federal de Alfenas
}

See next page for additional authors

Follow this and additional works at: https://digitalcommons.andrews.edu/pubs

Part of the Biochemical and Biomolecular Engineering Commons

\section{Recommended Citation}

Lopes, Emília Savioli; Leal Silva, Jean Felipe; Ccopa Rivera, Elmer; Gomes, Alana Petrina; Lopes, Melina Savioli; Maciel Filho, Rubens; and Tovar, Laura Plazas, "Challenges to Levulinic Acid and Humins Valuation in the Sugarcane Bagasse Biorefinery Concept" (2020). Faculty Publications. 1566.

https://digitalcommons.andrews.edu/pubs/1566

This Article is brought to you for free and open access by Digital Commons @ Andrews University. It has been accepted for inclusion in Faculty Publications by an authorized administrator of Digital Commons @ Andrews University. For more information, please contact repository@andrews.edu. 


\section{Authors}

Emília Savioli Lopes, Jean Felipe Leal Silva, Elmer Ccopa Rivera, Alana Petrina Gomes, Melina Savioli Lopes, Rubens Maciel Filho, and Laura Plazas Tovar 


\title{
Challenges to Levulinic Acid and Humins Valuation in the Sugarcane Bagasse Biorefinery Concept
}

\author{
Emília Savioli Lopes ${ }^{1}$ (D) - Jean Felipe Leal Silva ${ }^{1}$ (D) - Elmer Ccopa Rivera ${ }^{1,2} \cdot$ Alana Petrina Gomes $^{3}$. \\ Melina Savioli Lopes ${ }^{4} \cdot$ Rubens Maciel Filho $^{1}$ (D) - Laura Plazas $\operatorname{Tovar}^{3}$ (D) \\ Published online: 15 April 2020 \\ (C) Springer Science+Business Media, LLC, part of Springer Nature 2020
}

\begin{abstract}
Levulinic acid (LA) is currently one of the most promising chemicals derived from biomass. However, its large-scale production is hampered by the challenges in biomass hydrolysis and the poor selectivity due to the formation of humins (HUs). This study addresses these challenges using the biorefinery concept of biomass fractionation. A three-step process (pretreatment, delignification, and acid-catalyzed conversion) was optimized to produce LA from SCB considering the yield ( $\left.Y_{\mathrm{LA}}\right)$, efficiency $\left(E_{\mathrm{LA}}\right)$, and concentration of LA $\left(C_{\mathrm{LA}}\right)$ as functions of temperature, reaction time, acid concentration, and solids loading. By means of a multi-response optimization, values of $Y_{\mathrm{LA}}\left(20.9 \pm 1.25 \mathrm{~g} / 100 \mathrm{~g}_{\mathrm{ISF}-\mathrm{D}}\right), E_{\mathrm{LA}}(37.5 \pm 2.24 \mathrm{~mol} \%)$, and $C_{\mathrm{LA}}(25.1 \pm$ $1.50 \mathrm{~g} / \mathrm{L}$ ) were obtained at $180{ }^{\circ} \mathrm{C}, 75 \mathrm{~min}, 7.0 \% \mathrm{w} / \mathrm{v} \mathrm{H}_{2} \mathrm{SO}_{4}$, and $12.0 \% \mathrm{w} / \mathrm{v}$ of solids loading. Six scenarios for production of LA were analyzed in terms of yields of LA, HUs, lignin, and other sugar-derived products considering one-, two-, or three-step processes. The economic analysis indicated that the three-step scenario delivers better economic figures given that other valuable biomass fractions (hemicellulosic sugars and lignin) are better used and contribute to the overall economic performance of the process. The results also demonstrate the burden of HUs in the economics of the process because it was shown that the largest production of LA is also linked to the largest formation of HUs, which does not necessarily yield the best economic results. These findings indicate the importance of added value by-products for the profitable production of LA in biorefineries.
\end{abstract}

Keywords Biomass $\cdot$ Biorefinery $\cdot$ Humins $\cdot$ Levulinic acid $\cdot$ Optimization $\cdot$ Sugarcane bagasse

\section{Introduction}

Many solutions have been developed by the academy and industry to mitigate the consequences of the climate crisis, including the development of more sustainable processes [1]. The concept of biorefinery has been developed to fulfill

Electronic supplementary material The online version of this article (https://doi.org/10.1007/s12155-020-10124-9) contains supplementary material, which is available to authorized users.

Laura Plazas Tovar

laura.tovar@unifesp.br

1 School of Chemical Engineering, University of Campinas, Campinas, SP 13083-852, Brazil

2 Department of Engineering, Andrews University, Berrien Springs, MI 49104, USA

3 Department of Chemical Engineering, Federal University of São Paulo, Diadema, SP 09913-030, Brazil

4 Department of Chemical Engineering, Federal University of Alfenas, Pocos de Caldas, MG 37715-400, Brazil this purpose: in biorefineries, the biomass feedstock is transformed into many chemicals, fuels, and solid products depending on biomass composition [2]. Today, nearly 170 billion metric tons of biomass is produced annually, contributing to $10 \%$ of the primary energy market [3]. Brazil is one of the world leaders in the biomass market, and part of this success is attributed to the sugarcane industry. One of the products obtained from sugarcane is sugarcane bagasse (SCB), with a production of 180 million metric tons in the harvest of 2019-2020 [4]. Although today SCB is used mainly as a boiler fuel in sugarcane mills, it can be potentially used in the production of chemicals and fuels [5].

One of these chemicals is levulinic acid (LA, $\left.\mathrm{CH}_{3}(\mathrm{CO}) \mathrm{CH}_{2} \mathrm{CH}_{2} \mathrm{COOH}\right)$, a $\gamma$-keto acid obtained via hydrolysis sugars with applications in the chemical, food, agriculture, and fuel industry [6,7]. When biomass hydrolysis is carried out in an environment with severe oxidation strength, cellulose is hydrolyzed to glucose, whose dehydration yields in 5-hydroxymethylfurfural (5-HMF), which in turn can be decomposed in LA and formic acid (FA). Among the possible applications of LA, fuels and fuel additives deserve special 
attention because they present a vast market and demand low prices, which is possible for LA [8]. The first large-scale endeavor on the production of LA was based on the Biofine process, which consists of two reactors, each focused on different biomass fractions [9]. Fractionation of biomass for the production of LA is being investigated to create a better understanding of the advantages of this approach: Pradipta et al. [10] attained a yield of $43 \%$ from Indonesian SCB, Ji et al. [11] obtained a yield of 58\% from poplar wood, Jeong et al. [12] obtained $16.5 \%$ from Mongolian oak, and Liang et al. [13] obtained 39\% after 7 fed-batch steps. These results exemplify many approaches to biomass decomposition to sugars and its subsequent conversion to dehydration productions such as LA, FA, and furfural. However, little attention is given to the lignin fraction of biomass, which is usually discarded with the humins (HUs) produced during the hydrolysis process.

HUs are a solid condensation polymer resulting from the reactions between furans (furfural and 5-HMF) and sugars [11]. Other negative impacts are possible as well: HUs may deposit in the inner reactor wall (thus clogging the reactor) and reduce heat transfer efficiency. Another important factor to be considered is that cellulosic carbon is largely wasted as HUs, resulting in poor use of biomass sources in biorefineries focusing on LA [14]. Thus, it is important to define a compromise between the extent of these reactions to LA and HUs to maximize biomass conversion without losing selectivity to its many valuable products, which also include lignin, furfural, and other sugar derivatives.

This investigation proposes a multi-stage process for the production of LA and HUs from SCB. The yield $\left(Y_{\mathrm{LA}}\right)$, efficiency $\left(E_{\mathrm{LA}}\right)$, and concentration of LA $\left(C_{\mathrm{LA}}\right)$ were optimized considering the following parameters: temperature, reaction time, concentration of sulfuric acid, and solids loading. With the definition of the optimized operating conditions to produce LA, a multi-step strategy consisting of six scenarios was discussed in terms of selectivity and economic feasibility. This strategy addresses the biorefining of SCB to define opportunities to produce LA as well as HUs. Moreover, the obtained HUs were purified to provide a better understanding of its chemical composition and discuss the current challenges in making this solid material profitable in an economically attractive and integrated process.

\section{Materials and Methods}

\section{Materials}

SCB provided by "Usina São João" (Araras, São Paulo, Brazil) was dried under environmental conditions for 5 days until reaching an average moisture content of $5.0 \%$. The SCB without size reduction was homogenized in a single batch and stored in polyethylene bags. The composition of SCB was determined according to the standard analytical procedure detailed in "Characterization of Solid Fractions" and "Quantification of Carbohydrates, Organic Acids, and Furans." Type I ultrapure water and deionized water were prepared using a filter (Megapurity, Brazil, resistivity > 18.2 $\mathrm{M} \Omega \mathrm{cm}$ ). Suppliers and purities of reagents and chromatographic standards are listed in Table $\mathrm{S} 1-$ Supplementary Information.

\section{Processing Steps for Obtaining LA}

Figure 1 shows a scheme of the experimental setup and the trial sequence described in this section of the methodology.

\section{Pretreatment with Sulfuric Acid (PT)}

SCB was subjected to dilute sulfuric acid $(1.0 \% \mathrm{w} / \mathrm{v})$ with a solids loading of $20.0 \% \mathrm{w} / \mathrm{v}$. The process was carried out in a vertical autoclave at $121^{\circ} \mathrm{C}$ for $80 \mathrm{~min}$. After PT, the resulting slurry was submitted to filtration. The insoluble solid fraction (ISF) was neutralized with approximately $1 \mathrm{~L}$ of distilled water until the $\mathrm{pH}$ of the resulting liquid was near 6 . With $7.8 \%$ of moisture, the ISF was stored in polyethylene bags to be submitted to delignification. The ISF was characterized according to the method described in "Characterization of Solid Fractions." The resulting liquid, named acid hydrolysate-I (AH-I), was characterized according to the methods described in "Characterization of Liquid Fractions" and "Quantification of Carbohydrates, Organic Acids, and Furans."

\section{Delignification (DL)}

ISF was mixed to solution of $\mathrm{NaOH}(0.5 \% \mathrm{w} / \mathrm{v})$ with solids loading of $20.0 \% \mathrm{w} / \mathrm{v}$ for $90 \mathrm{~min}$. DL was carried out for $90 \mathrm{~min}$ at $80^{\circ} \mathrm{C}$, with temperature-controlled by a thermostatic bath Marconi MA 108/9 (Marconi, Brazil). After DL, the insoluble solid fraction - delignified (ISF-D) was neutralized with approximately $1 \mathrm{~L}$ of distilled water until the $\mathrm{pH}$ of the resulting liquid was 6 . With $6.2 \%$ of moisture, ISF-D was stored in polyethylene bags until being submitted to a catalyzed conversion with an acid catalyst. The ISF-D was characterized according to the method described in "Characterization of Solid Fractions."

\section{Acid-catalyzed conversion (ACC)}

Experiments were made in a bench system composed of two vessels of stainless steel of $300 \mathrm{~mL}$ each, with an internal diameter of $70 \mathrm{~mm}$ and a wall thickness of $5 \mathrm{~mm}$. Each vessel contains a pressure gauge, a temperature controller, and a mica band heater of $1 \mathrm{~kW}$. The reactor has limits of operation of 


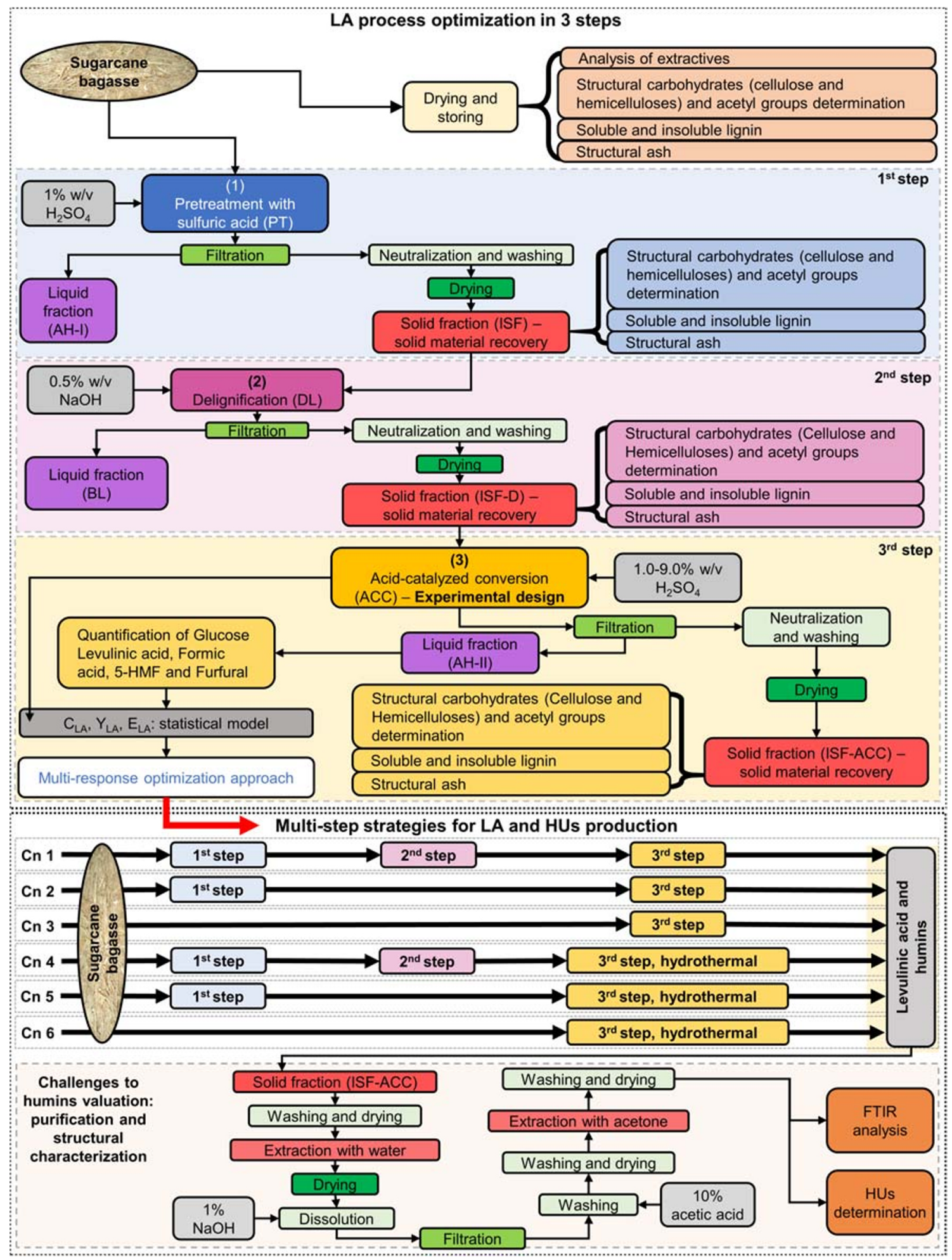

Fig. 1 Schematic of the experimental setup and the trial sequence

$200{ }^{\circ} \mathrm{C}$ and 20 bar. After turning on, the reactor demands from 10 to $20 \mathrm{~min}$ to reach temperatures from 150 until $190{ }^{\circ} \mathrm{C}$.

First, a sample of ISF-D was weighted according to the equivalent solids loading desired $(8.0-14.0 \% \mathrm{w} / \mathrm{v})$. The samples were transferred to the bench reaction system with the acid solution of $\mathrm{H}_{2} \mathrm{SO}_{4}(1.0-9.1 \%)$ w/v. After each ACC run, the reactor was turned off and quenched in water. The resulting slurry was filtered, and the solid fraction, named insoluble solid fraction (ISF-ACC), was neutralized with approximately $2-4 \mathrm{~L}$ of distilled water, depending on the 
concentration of the acid solution, until the $\mathrm{pH}$ of the resulting liquid was near 6. Quantification of total solids and composition of liquor (named acid hydrolysate-II, AH-II) followed the procedures mentioned in "Characterization of Solid Fractions," "Characterization of Liquid Fractions," and "Quantification of Carbohydrates, Organic Acids, and Furans."

\section{Characterization of Solid Fractions}

The composition of SCB was determined via analysis of extractives [15], structural carbohydrates, acetyl groups [16], soluble and insoluble lignin [17], and ash [18]. The compositions of the other fractions, ISF, ISF-D, and ISF-CCA were determined in the same way, except by the analysis of extractives. All analyses were carried out in triplicate.

\section{Analysis of Extractives}

Approximately $3 \mathrm{~g}$ of milled in natura $\mathrm{SCB}$ was contacted with cyclohexane and ethanol $(\mathrm{v} / \mathrm{v}, 1: 1)$ for $48 \mathrm{~h}$ in Soxhlet extractor, followed by aqueous extraction (using deionized water) for $20 \mathrm{~h}$. After the analysis of extractives, SCB was dried at $105{ }^{\circ} \mathrm{C}$ for $24 \mathrm{~h}$, milled, and homogenized before structural carbohydrate analysis.

\section{Structural Carbohydrates and Acetyl Groups}

Samples from extracted SCB and ISF, ISF-D, and ISF-CCA were analyzed by two-step acid hydrolysis. Samples (300.0 \pm $10.0 \mathrm{mg}$ ) were hydrolyzed with $72 \%$ sulfuric acid $(3 \mathrm{~mL})$ at $30{ }^{\circ} \mathrm{C}$ for $1 \mathrm{~h}$. Deionized water was added to dilute the acid to a $4 \%$ concentration (addition of $84 \mathrm{~mL}$ ). The mixture was transferred to laboratory bottles (GL 45 screw top, Schott Duran, Germany) and heated to $121^{\circ} \mathrm{C}$ for $1 \mathrm{~h}$ in a vertical autoclave. After that, the hydrolysates were quenched before the removal of the caps. The hydrolysates were filtered through a previously weighed dry filter paper. An aliquot was filtered through Millipore membranes (mixed cellulose esters, $0.22 \mu \mathrm{m}, 13 \mathrm{~mm}$, white, plain filter), and the filtrates were stored at $-2{ }^{\circ} \mathrm{C}$ for analysis via chromatography. The solids were washed to a pH of 6 and oven-dried $\left(105^{\circ} \mathrm{C}\right)$ for $48 \mathrm{~h}$ to a constant weight.

\section{Structural Lignin}

Acid-insoluble lignin was determined by subtracting the ash content from the mass of dried material at $105^{\circ} \mathrm{C}$ as described in previous literature [17]. The acid-soluble lignin in the filtrate was determined by measuring the absorbance at $280 \mathrm{~nm}$ and using a correlation described in previous literature [17]. For this procedure, a $1 \mathrm{~mL}$ sample of the filtrate was pipetted into a $25 \mathrm{~mL}$ volumetric flask and alkalinized to $\mathrm{pH} 12$ with
6.5 $\mathrm{M} \mathrm{NaOH}$, and the volume was completed with deionized water. The total lignin content in the SCB, ISF, ISF-D, and ISF-CCA was calculated as the sum of acid-insoluble and acid-soluble lignin.

\section{Structural Ash}

Total ash was determined by gravimetry: the dried solids were transferred to a weighed crucible and heated in a muffle furnace to $300^{\circ} \mathrm{C}$ for $1 \mathrm{~h}$ and then heated to $800{ }^{\circ} \mathrm{C}$ for $2 \mathrm{~h}$.

\section{Characterization of Liquid Fractions}

The chemical composition of AH-I and AH-II was determined via chromatography [19]. For each sample, the $\mathrm{pH}$ was measured and recorded to the nearest $0.01 \mathrm{pH}$ unit, and aliquots of $5 \mathrm{~mL}$ of each sample were pipetted in triplicate into glass tubes. The volume of $72 \%$ sulfuric acid required to bring the acid concentration to a final concentration of $4 \%$ was then calculated to treat the samples in the first step [19]. Acid hydrolysis was carried out using $4 \% \mathrm{H}_{2} \mathrm{SO}_{4}$ and the samples were autoclaved for $1 \mathrm{~h}$ at $121{ }^{\circ} \mathrm{C}$. Then, the hydrolysates were cooled to room temperature. The hydrolysates were filtered through Millipore membranes (mixed cellulose esters, $0.22 \mu \mathrm{m}, 13 \mathrm{~mm}$, white, plain filter), and the filtrates were stored at $-2{ }^{\circ} \mathrm{C}$ for analysis.

\section{Quantification of Carbohydrates, Organic Acids, and Furans}

The composition was determined in an HPLC system (Agilent 1260 Infinity II, Agilent Technologies, USA) equipped with a quaternary pump G1311B, a refractive index detector G1362A, and diode array detector G4212B. Cellobiose, glucose, xylose, arabinose, acetic acid, FA, and LA were separated in a Bio-Rad® column HPX-87H $(9 \mu \mathrm{m}, 300 \times 7.8 \mathrm{~mm})$ operated at $35^{\circ} \mathrm{C}$, in isocratic elution using $5 \mathrm{mM}$ of $\mathrm{H}_{2} \mathrm{SO}_{4}$ at a flow rate of $0.6 \mathrm{~mL} / \mathrm{min}$, with a sample injection of $15 \mu \mathrm{L}$ and a run time of $25 \mathrm{~min}$. For these chemicals, the signal was measured using the refractive index detector. Chemicals were identified based on retention time and elution of the standards. Quantification was performed by the external standard method. Calibration curves (plotted with 11 different concentrations) were established using a mixture of cellobiose, glucose, xylose, and arabinose standards, at concentrations ranging from 0.1 to $4 \mathrm{~g} / \mathrm{L}$. Concentrations of standards for organic acids (LA and FA) ranged from 0.1 to $10 \mathrm{~g} / \mathrm{L}$.

Furfural and 5-HMF were separated in Nova-Pak C18 column $(4 \mu \mathrm{m}, 4.6 \mathrm{~mm} \times 150 \mathrm{~mm})$ at $30{ }^{\circ} \mathrm{C}$ with the diode array detector at $280 \mathrm{~nm}$ using an eluent composed of 1:8 $\mathrm{v} / \mathrm{v}$ solution of acetonitrile-water and $1 \% \mathrm{w} / \mathrm{w}$ of acetic acid in a flow rate of $0.8 \mathrm{~mL} / \mathrm{min}$. Furfural and 5-HMF were quantified by the external standard method. 
Calibration curves (plotted with 16 different concentrations) were established using a mixture of furfural and 5HMF standards, at concentrations ranging from 0 to $1 \mathrm{~g} / \mathrm{L}$. Data were processed using the software OpenLAB CDS ChemStation Edition C.01.05 (Agilent Technologies, USA, 2013). Some examples of chromatograms are displayed in the Supplementary Information-S2.

\section{Definition of Yield and Efficiency of LA}

The theoretical yield $\left(Y_{\mathrm{T}, \mathrm{LA}}\right)$ and the LA yield based on the fraction of ISF-D $\left(Y_{\mathrm{LA}}\right)$ were calculated according to Eqs. (1) and (2), respectively.

$Y_{\mathrm{T}, \mathrm{LA}}(\%)=$ Cellulose content $(\mathrm{g}) \times 0.715 / \operatorname{substrate}(\mathrm{g}) \cdot(1)$

$Y_{\mathrm{LA}}(\mathrm{g} / 100 \mathrm{~g})=[\mathrm{LA}(\mathrm{g}) / \operatorname{substrate}(\mathrm{g})] \times 100$.

where "substrate" is understood as follows: in the three-step fractionation, the substrate is ISF-D; in the two-step fractionation, the substrate is ISF; and in the one-step fractionation, the substrate is SCB.

Efficiency $\left(E_{\mathrm{LA}}\right)$ is the theoretical yield based on celullose content, expressed by Eq. (3) [20].

$E_{\mathrm{LA}}(\mathrm{mol} \%)=\left[Y_{\mathrm{LA}} / Y_{\mathrm{T}, \mathrm{LA}}\right] \times 100$.

\section{Experimental Design and Statistical Analysis}

When considering a fractionation of SCB in three steps, the ACC runs were performed for the production of LA and the experiments were based in a $2^{4}$ central composite design with three replicates in the central point and 8 axial points totalizing 27 trials (all experiments were performed in triplicate). The effects of solids loading $(S)$, reaction time $(t)$, temperature $(T)$, and acid concentration $(A)$ were analyzed in 5 codified levels (Table 1). The concentration of LA $\left(C_{\mathrm{LA}}\right)$, the yield regarding the fraction ISF-D $\left(Y_{\mathrm{LA}}\right)$, and the efficiency $\left(E_{\mathrm{LA}}\right)$ were used as response variables. The software StatSoft Statistica 7.0 was used on the analysis of the data obtained. The significance of variables and their interactions were determined with a $98 \%$ confidence interval.

Table 1 Coded and real variables chosen in the design of experiments

\begin{tabular}{llllll}
\hline Variables (coded parameters) & \multicolumn{5}{l}{ Levels } \\
\cline { 2 - 6 } & -2 & -1 & 0 & 1 & 2 \\
\hline$S(\% \mathrm{w} / \mathrm{v})(\mathrm{X} 1)$ & 6.0 & 8.0 & 10.0 & 12.0 & 14.0 \\
$t(\mathrm{~min})(\mathrm{X} 2)$ & 35 & 55 & 75 & 95 & 115 \\
$T\left({ }^{\circ} \mathrm{C}\right)(\mathrm{X} 3)$ & 150 & 160 & 170 & 180 & 190 \\
$A(\% \mathrm{w} / \mathrm{v})(\mathrm{X} 4)$ & 1.0 & 3.0 & 5.0 & 7.0 & 9.0 \\
\hline
\end{tabular}

\section{Statistical Model Development}

The statistical model for each response $\left(C_{\mathrm{LA}}, Y_{\mathrm{LA}}\right.$, and $\left.E_{\mathrm{LA}}\right)$ was approximated by the second-order polynomial model presented in Eq. (4):

$$
\begin{aligned}
Z_{i}=\alpha_{0} & +\alpha_{1} \times(S)+\alpha_{2} \times(t)+\alpha_{3} \times(T)+\alpha_{4} \times(A) \\
& +\alpha_{11} \times(S \times S)+\alpha_{22}(t \times t)+\alpha_{33}(T \times T) \\
& +\alpha_{44}(A \times A)+\alpha_{12}(S \times t)+\alpha_{13}(S \times T) \\
& +\alpha_{14}(S \times A)+\alpha_{23}(t \times T)+\alpha_{24}(t \times A) \\
& +\alpha_{34}(T \times A) .
\end{aligned}
$$

where $Z_{i}$ correspond to each predicted response $\left(C_{\mathrm{LA}}, Y_{\mathrm{LA}}\right.$, and $\left.E_{\mathrm{LA}}\right) ; \alpha_{0}$ is a constant; $\alpha_{1}, \alpha_{2}, \alpha_{3}$, and $\alpha_{4}$ are linear coefficients; $\alpha_{11}, \alpha_{22}, \alpha_{33}$, and $\alpha_{44}$ are quadratic coefficients; and $\alpha_{12}, \alpha_{13}, \alpha_{14}, \alpha_{23}, \alpha_{24}$, and $\alpha_{34}$ are the coefficients of the interaction terms. The regression coefficients were obtained, and the response surfaces of the significant binary interactions were plotted. The validation of the statistical models was determined by Fisher's distribution test ( $F$ test), and the quality of the fitted surface was assessed with the squared correlation coefficients $\left(R^{2}\right)$. The statistical model presented in Eq. (4) was used to predict the optimized hydrolysis conditions and, which were then validated experimentally.

\section{Multi-response Optimization Approach}

Following Derringer's desirability function, responses $C_{\mathrm{LA}}$, $Y_{\mathrm{LA}}$, and $E_{\mathrm{LA}}$ were simultaneously optimized [21]. This function transforms each response in $d_{i}$ values between 0 and 1 (from response completely undesired to response completely desired). Global desirability index $D$ is given by Eq. (5), which is the geometric mean from the combination of each one of the transformed responses:

$D=\left(d_{1}^{r_{1}} \times d_{2}^{r_{2}} \times d_{3}^{r_{3}}\right)^{1 / \Sigma r_{i}}$

where $d_{i}$ is the response of desirability of each response and $r_{i}$ is the importance of each variable regarding the others, with values between 0 and 1 and $r_{1}+r_{2}+r_{3}=1$. Considering that $C_{\mathrm{LA}}, Y_{\mathrm{LA}}$, and $E_{\mathrm{LA}}$ have the same importance, thus $r_{1}=r_{2}=$ $r_{3}=1 / 3$. In order to maximize the responses, $d_{i}$ assumes values of 1 , and when all responses reach their maximum value, $D$ is equal to 1 [22].

After analyzing the multi-response optimization as a function of $C_{\mathrm{LA}}, Y_{\mathrm{LA}}$, and $E_{\mathrm{LA}}$, it was needed to evaluate if the use of a three-step process is feasible for the conversion of SCB to LA taking into consideration the production of HUs. The definition of the strategy adopted is presented in the next section.

\section{Multi-step Strategies for Production of LA and HUs}

This section aims to investigate the production of LA from SCB in different process steps and the consequent formation 
of HUs. When evaluating different treatment steps (e.g., hydrothermal decomposition and hydrothermal decomposition catalyzed by acid), it is possible to ally the primary and secondary biorefining to make a process more or less selective to LA. In order to evaluate the efficiency of the process proposed in this study, PT, DL, and ACC were combined in different scenarios. PT operating conditions were $120^{\circ} \mathrm{C}, 80 \mathrm{~min}$, $20.0 \% \mathrm{w} / \mathrm{v}$ of solids loading, and $1.0 \% \mathrm{w} / \mathrm{v} \mathrm{H}_{2} \mathrm{SO}_{4}$, and DL operating conditions were $80^{\circ} \mathrm{C}, 90 \mathrm{~min}, 2.0 \% \mathrm{w} / \mathrm{v}$ of solids loading, and $0.5 \% \mathrm{w} / \mathrm{v} \mathrm{NaOH}$. Operating conditions for ACC were the optimized conditions obtained according to "Multiresponse Optimization Approach."

In the first scenario (named Cn1), SCB was submitted to a three-step conversion: PT followed by DL and then ACC. The second scenario $(\mathrm{Cn} 2)$ consisted of PT followed by ACC. The third scenario $(\mathrm{Cn} 3)$ consisted of a single-step ACC. The other three scenarios (named $\mathrm{Cn} 4, \mathrm{Cn} 5$, and $\mathrm{Cn} 6$ ) consisted of replacing ACC by a hydrothermal step with no addition of $\mathrm{H}_{2} \mathrm{SO}_{4}$. After executing the experiments, the resulting slurry was filtered through a Buchner funnel. The hydrolysate was analyzed according to the method described in "Characterization of Liquid Fractions" and "Quantification of Carbohydrates, Organic Acids, and Furans," whereas the insoluble solid fractions (ISF-ACCs) were analyzed according to the method described in "Characterization of Solid Fractions."

\section{HUs Purification and Structural Characterization}

The HUs were determined according to the methodology described by Hoang et al. [23]. To remove the residual sugar, the residual solid (ISF-ACC) was contacted with deionized water for $48 \mathrm{~h}$ in a Soxhlet extractor. After that, the solid was ovendried at $105{ }^{\circ} \mathrm{C}$ to constant weight. Subsequently, the total solid material was dispersed on $150 \mathrm{~mL}$ of $1 \% \mathrm{NaOH}$ solution and kept at $95^{\circ} \mathrm{C}$ for $1 \mathrm{~h}$ at constant stirring. The solids were thrice washed in a $10 \%$ acetic acid solution in a proportion of 4:1 (liquid to solid) and then washed with water at $80^{\circ} \mathrm{C}$ to reach a $\mathrm{pH}$ of 6 . Finally, the material (filter paper and retained solids) was oven-dried at $105{ }^{\circ} \mathrm{C}$ to constant weight. After treatment with $\mathrm{NaOH}$, the resulting filter paper and solids were contacted with acetone in a Soxhlet extractor (six

Table 2 Prices of feedstock and products considered in the economic analysis. All values were updated to December 2019 using appropriate indexes and exchange rates $[8,26$, 27]

\begin{tabular}{ll}
\hline Feedstock or product & Price $(\$ / \mathrm{t})$ \\
\hline SCB $(50 \%$ moisture $)$ & 26 \\
Lignin & 301 \\
Ethanol & 602 \\
LA & 8906 \\
Formic acid & 496 \\
Furfural & 1591 \\
\hline
\end{tabular}

refluxes per hour for $18 \mathrm{~h}$ ). Then, the solids were washed and oven-dried at $105{ }^{\circ} \mathrm{C}$ to constant weight.

The resulting solid samples from the analysis of the six scenarios (referred to as HUs) and the SCB were analyzed in a Fourier transform infrared spectrometer (Thermo Scientific Nicolet 6700, Madison, USA). The measurement was conducted twice, using the accessory snap-in baseplate $(\mathrm{KBr}$ method). The detected spectra are the absorbance of the samples in the wave number range of $4000-400 \mathrm{~cm}^{-1}$, resolution of $4 \mathrm{~cm}^{-1}$, and scan of 32 .

\section{Economic Analysis of Multi-step Conversion}

A brief economic analysis was carried out to analyze the impact of the multi-step strategy in the production of LA from $\mathrm{SCB}$. The analysis considered the process feedstock (SCB), other required process inputs, and the obtained products (LA, FA, furfural, and HUs) to calculate the earnings before interest, taxes, depreciation, and amortization (EBITDA). The EBITDA was used to estimate the EBITDA margin, which is the ratio between EBITDA and revenue. The following assumptions were considered in the analysis: (i) SCB was available with $50 \%$ moisture; (ii) the sugars removed during PT were converted into ethanol via fermentation with $90 \%$ efficiency for glucose, $80 \%$ efficiency for xylose, and a steam demand of $9.8 \mathrm{~kg} / \mathrm{kg}$ for recovery [24]; (iii) a steam demand of $9.1 \mathrm{~kg} / \mathrm{kg}$ was assumed in the recovery of LA, FA, and furfural

Table 3 Chemical composition of SCB, ISF, ISF-D, and recovery yield of pretreatment fractions. Data represent the mean ( \pm standard deviation)

\begin{tabular}{llll}
\hline & SCB & ISF & ISF-D \\
\hline Content (w/w) & & & \\
Cellulose & $40.5 \pm 2.17$ & $62.5 \pm 1.33$ & $78.0 \pm 0.51$ \\
Hemicelluloses & $26.5 \pm 2.33$ & $12.5 \pm 1.70$ & $6.4 \pm 0.45$ \\
Acetyl groups & $3.6 \pm 1.11$ & - & - \\
Lignin & $19.1 \pm 3.18$ & $23.2 \pm 1.89$ & $7.4 \pm 0.45$ \\
Extractives & $8.9 \pm 0.06$ & - & - \\
Ash & $2.5 \pm 0.12$ & $1.8 \pm 0.03$ & $2.1 \pm 1.18$ \\
Total & $101.1 \pm 1.64$ & $100 \pm 2.04$ & $93.9 \pm 1.47$ \\
Composition (\%) & & & \\
Cellulose & & $36.7 \pm 0.11$ & $36.7 \pm 0.16$ \\
Hemicelluloses & & $7.3 \pm 1.17$ & $3.0 \pm 0.14$ \\
Lignin & & $13.6 \pm 1.25$ & $3.5 \pm 0.14$ \\
Solid recovery & & $58.8 \pm 1.34$ & $47.1 \pm 0.46$ \\
Recovery ${ }^{\mathrm{a}} \%$ ) & & & \\
Cellulose & & $90.8 \pm 1.40$ & $90.8 \pm 0.49$ \\
Hemicelluloses & & $27.6 \pm 1.10$ & $13.2 \pm 2.40$ \\
Lignin & & $72.1 \pm 1.12$ & $16.7 \pm 1.97$ \\
\hline
\end{tabular}

${ }^{\mathrm{a}}$ The recovery is defined as the fraction of the cellulose, hemicelluloses, or lignin remaining in the solid fraction (ISF or ISF-D) after treatments compared to what was available in SCB 
Table 4 Concentration of residual sugar (glucose (GLC)) and intermediary byproducts (furfural (FUR), 5hydroxymethylfurfural (5-HMF) and formic acid (FA)) obtained in the 27 trials of the design of experiments

\begin{tabular}{|c|c|c|c|c|c|c|c|c|}
\hline \multirow[t]{2}{*}{ Trial } & \multirow[t]{2}{*}{$S(\% \mathrm{w} / \mathrm{v})$} & \multirow[t]{2}{*}{$t(\min )$} & \multirow[t]{2}{*}{$T\left({ }^{\circ} \mathrm{C}\right)$} & \multirow[t]{2}{*}{$A(\% \mathrm{w} / \mathrm{v})$} & \multicolumn{4}{|c|}{ Concentration $(\mathrm{g} / \mathrm{L})$} \\
\hline & & & & & GLC & FUR & 5-HMF & FA \\
\hline 1 & 14.0 & 75 & 170 & 5.0 & $0.4 \pm 0.03$ & $0.5 \pm 0.05$ & $0.2 \pm 0.02$ & $2.3 \pm 0.03$ \\
\hline 2 & 8.0 & 55 & 180 & 3.0 & $0.1 \pm 0.02$ & $0.3 \pm 0.09$ & $0.1 \pm 0.01$ & $1.3 \pm 0.03$ \\
\hline 3 & 12.0 & 95 & 180 & 3.0 & $0.1 \pm 0.05$ & $0.2 \pm 0.02$ & $0.0 \pm 0.02$ & $1.7 \pm 0.04$ \\
\hline 4 & 12.0 & 95 & 180 & 7.0 & $0.0 \pm 0.00$ & $0.0 \pm 0.01$ & $0.0 \pm 0.00$ & $2.8 \pm 0.04$ \\
\hline 5 & 8.0 & 95 & 160 & 7.0 & $0.1 \pm 0.03$ & $0.2 \pm 0.05$ & $0.1 \pm 0.02$ & $1.7 \pm 0.07$ \\
\hline 6 & 10.0 & 35 & 170 & 5.0 & $0.3 \pm 0.06$ & $0.5 \pm 0.19$ & $0.0 \pm 0.00$ & $2.5 \pm 0.03$ \\
\hline 7 & 10.0 & 75 & 170 & 5.0 & $0.2 \pm 0.01$ & $0.4 \pm 0.02$ & $0.1 \pm 0.01$ & $2.3 \pm 0.04$ \\
\hline 8 & 6.0 & 75 & 170 & 5.0 & $0.0 \pm 0.00$ & $0.2 \pm 0.03$ & $0.0 \pm 0.00$ & $1.7 \pm 0.07$ \\
\hline 9 & 10.0 & 115 & 170 & 5.0 & $0.1 \pm 0.01$ & $0.1 \pm 0.03$ & $0.0 \pm 0.00$ & $1.3 \pm 0.02$ \\
\hline 10 & 10.0 & 75 & 190 & 5.0 & $0.0 \pm 0.00$ & $0.1 \pm 0.02$ & $0.0 \pm 0.00$ & $1.8 \pm 0.12$ \\
\hline 11 & 10.0 & 75 & 150 & 5.0 & $1.8 \pm 0.08$ & $0.7 \pm 0.10$ & $0.1 \pm 0.03$ & $1.6 \pm 0.06$ \\
\hline 12 & 10.0 & 75 & 170 & 5.0 & $0.0 \pm 0.01$ & $0.3 \pm 0.03$ & $0.0 \pm 0.00$ & $2.3 \pm 0.10$ \\
\hline 13 & 12.0 & 95 & 160 & 7.0 & $0.1 \pm 0.01$ & $0.2 \pm 0.01$ & $0.0 \pm 0.00$ & $2.7 \pm 0.03$ \\
\hline 14 & 8.0 & 55 & 160 & 7.0 & $0.2 \pm 0.02$ & $0.5 \pm 0.06$ & $0.1 \pm 0.03$ & $1.1 \pm 0.04$ \\
\hline 15 & 12.0 & 55 & 160 & 3.0 & $3.4 \pm 0.01$ & $1.1 \pm 0.05$ & $0.2 \pm 0.01$ & $2.0 \pm 0.04$ \\
\hline 16 & 10.0 & 75 & 170 & 5.0 & $0.3 \pm 0.02$ & $0.5 \pm 0.07$ & $0.1 \pm 0.02$ & $2.4 \pm 0.03$ \\
\hline 17 & 12.0 & 55 & 180 & 7.0 & $0.0 \pm 0.00$ & $0.1 \pm 0.03$ & $0.0 \pm 0.00$ & $2.9 \pm 0.15$ \\
\hline 18 & 12.0 & 95 & 160 & 3.0 & $0.8 \pm 0.01$ & $1.0 \pm 0.25$ & $0.3 \pm 0.11$ & $1.1 \pm 0.12$ \\
\hline 19 & 12.0 & 55 & 160 & 7.0 & $0.5 \pm 0.06$ & $0.6 \pm 0.01$ & $0.1 \pm 0.01$ & $1.8 \pm 0.04$ \\
\hline 20 & 8.0 & 95 & 180 & 3.0 & $0.0 \pm 0.01$ & $0.2 \pm 0.04$ & $0.0 \pm 0.00$ & $1.4 \pm 0.12$ \\
\hline 21 & 8.0 & 55 & 180 & 7.0 & $0.0 \pm 0.00$ & $0.2 \pm 0.06$ & $0.0 \pm 0.00$ & $2.3 \pm 0.07$ \\
\hline 22 & 8.0 & 55 & 160 & 3.0 & $1.8 \pm 0.12$ & $0.8 \pm 0.06$ & $0.1 \pm 0.05$ & $1.5 \pm 0.04$ \\
\hline 23 & 12.0 & 55 & 180 & 3.0 & $0.0 \pm 0.00$ & $0.5 \pm 0.10$ & $0.0 \pm 0.00$ & $2.7 \pm 0.06$ \\
\hline 24 & 8.0 & 95 & 180 & 7.0 & $0.0 \pm 0.00$ & $0.0 \pm 0.01$ & $0.0 \pm 0.00$ & $2.2 \pm 0.16$ \\
\hline 25 & 10.0 & 75 & 170 & 1.0 & $1.0 \pm 0.04$ & $1.1 \pm 0.11$ & $0.4 \pm 0.08$ & $0.8 \pm 0.02$ \\
\hline 26 & 10.0 & 75 & 170 & 9.0 & $0.0 \pm 0.00$ & $0.1 \pm 0.01$ & $0.0 \pm 0.00$ & $1.8 \pm 0.09$ \\
\hline 27 & 8.0 & 95 & 160 & 3.0 & $0.6 \pm 0.01$ & $0.7 \pm 0.04$ & $0.1 \pm 0.02$ & $0.8 \pm 0.02$ \\
\hline
\end{tabular}

[25]; (iv) residues after ACC (humins and residual cellulignin) were used as supplementary boiler fuel capable of providing half of the steam provided by SCB; (v) prices were based on previous literature and updated to December 2019 (Table 2) $[8,26]$; (vi) lignin is a product only in scenarios with DL, and is sold as soda-lignin [27]. It is important to mention that LA is currently commercialized in the specialties markets with a market price of nearly $\$ 10 / \mathrm{kg}$ [28]. Nevertheless, this price is incompatible with the commodities market, and much lower prices are possible [29]. Therefore, besides calculating the EBITDA margin with the price for the specialties market, a minimum selling price (MSP) of LA was determined to attain an EBITDA margin of $30 \%$ which is acceptable in the chemical industry [8].

\section{Results and Discussion}

PT of SCB yielded the ISF, also called cellulignin. According to the chemical composition of ISF (Table 3), the recovery of solid material after PT was $58.8 \%$, indicating that nearly onethird of SCB was solubilized. The hemicelluloses were the most solubilized fraction, from $26.5 \%$ they were reduced to $12.5 \%$ after PT. DL removed $75.4 \%$ of lignin with a recovery of solid material of $80.0 \%$. The total mass obtained after DL is equivalent to $44.2 \%$, representing a recovery of $75.0 \%$ of cellulignin in this second step. Analyzing ISF-D, it is possible to note a high recovery yield of cellulose $(90.8 \%)$ and the content of hemicelluloses is low $(6.4 \%)$ due to the previous PT.

Table 4 reports the concentrations of residual glucose, 5HMF, furfural, and FA obtained in the liquid fraction of the 27 runs of ACC of the design of experiments, whereas the $C_{\mathrm{LA}}$, $Y_{\mathrm{LA}}$, and $E_{\mathrm{LA}}$ are reported in Table 5. Minimum amounts of arabinose were found. Relatively low yields of intermediary byproducts were observed: furfural yields were between 0.04 and $1.2 \mathrm{~g} / 100 \mathrm{~g}_{\text {ISF-D }}$, and 5-HMF yields between 0.0 and $0.5 \mathrm{~g} /$ $100 \mathrm{~g}_{\text {ISF-D. }}$ Also, in the cellulose depolymerization-catalyzed system, $\mathrm{H}_{2} \mathrm{SO}_{4}$ influenced residual glucose, 5-HMF and furfural yields, and their composition. The highest residual 
Table 5 Results of the design of experiments used in process optimization. In the responses, the value predicted by the fitted model is indicated between parentheses

\begin{tabular}{|c|c|c|c|c|c|c|c|}
\hline \multirow[t]{2}{*}{ Trial } & \multicolumn{4}{|c|}{ Coded variables } & \multicolumn{3}{|l|}{ Responses } \\
\hline & $(\mathrm{X} 1)$ & $(\mathrm{X} 2)$ & (X3) & (X4) & $C_{\mathrm{LA}}(\mathrm{g} / \mathrm{L})$ & $Y_{\mathrm{LA}}\left(\mathrm{g} / 100 \mathrm{~g}_{\mathrm{ISF}-\mathrm{D}}\right)$ & $E_{\mathrm{LA}}(\mathrm{mol} \%)$ \\
\hline 1 & +2 & 0 & 0 & 0 & $24.9 \pm 0.26(26.8)$ & $17.8 \pm 0.18$ & $30.9 \pm 0.33(36.8)$ \\
\hline 2 & -1 & -1 & +1 & -1 & $10.2 \pm 0.35(14.9)$ & $12.7 \pm 0.01$ & $22.8 \pm 0.03(32.6)$ \\
\hline 3 & +1 & +1 & +1 & -1 & $12.8 \pm 0.11(10.9)$ & $10.7 \pm 0.09(7.8)$ & $19.1 \pm 0.17(14.0)$ \\
\hline 4 & +1 & +1 & +1 & +1 & $27.3 \pm 0.70(26.1)$ & $22.8 \pm 0.58(21.7)$ & $40.7 \pm 1.05(38.8)$ \\
\hline 5 & -1 & +1 & -1 & +1 & $15.3 \pm 0.76(15.0)$ & $19.2 \pm 0.95(18.4)$ & $34.3 \pm 1.70(32.9)$ \\
\hline 6 & 0 & -2 & 0 & 0 & $22.4 \pm 0.42(20.1)$ & $22.4 \pm 0.41(19.6)$ & $40.1 \pm 0.75$ \\
\hline 7 & 0 & 0 & 0 & 0 & $24.4 \pm 0.47(23.3)$ & $24.4 \pm 0.47(23.3)$ & $43.6 \pm 0.85(41.8)$ \\
\hline 8 & -2 & 0 & 0 & 0 & $14.9 \pm 0.61(14.1)$ & $24.9 \pm 1.02(22.4)$ & $44.7 \pm 1.83(40.0)$ \\
\hline 9 & 0 & +2 & 0 & 0 & $10.3 \pm 0.13(13.7)$ & $10.3 \pm 0.13(13.6)$ & $18.4 \pm 0.24(24.5)$ \\
\hline 10 & 0 & 0 & +2 & 0 & $15.5 \pm 1.10(19.2)$ & $15.5 \pm 1.09(18.9)$ & $27.7 \pm 1.97(34.0)$ \\
\hline 11 & 0 & 0 & -2 & 0 & $13.4 \pm 0.81(10.8)$ & $13.4 \pm 0.81(10.5)$ & $24.1 \pm 1.46(19.0)$ \\
\hline 12 & 0 & 0 & 0 & 0 & $22.5 \pm 1.41(23.3)$ & $22.5 \pm 1.41(23.3)$ & $40.4 \pm 2.53(41.8)$ \\
\hline 13 & +1 & +1 & -1 & +1 & $24.3 \pm 0.25(20.1)$ & $20.3 \pm 0.20(16.4)$ & $36.3 \pm 0.38(29.3)$ \\
\hline 14 & -1 & -1 & -1 & +1 & $7.5 \pm 0.38(9.9)$ & $9.4 \pm 0.48(13.7)$ & $16.8 \pm 0.86(24.7)$ \\
\hline 15 & +1 & -1 & -1 & -1 & $17.3 \pm 0.48(17.5)$ & $14.5 \pm 0.40(15.3)$ & $25.9 \pm 0.73(27.8)$ \\
\hline 16 & 0 & 0 & 0 & 0 & $23.2 \pm 0.07(23.3)$ & $23.2 \pm 0.07$ & $41.5 \pm 0.14(41.8)$ \\
\hline 17 & +1 & -1 & +1 & +1 & $28.4 \pm 1.49(27.1)$ & $23.7 \pm 1.24(22.3)$ & $42.4 \pm 2.22(39.8)$ \\
\hline 18 & +1 & +1 & -1 & -1 & $7.1 \pm 1.04(8.9)$ & $5.9 \pm 0.86(7.1)$ & $10.7 \pm 1.55(12.7)$ \\
\hline 19 & +1 & -1 & -1 & -1 & $15.4 \pm 0.45(18.2)$ & $12.9 \pm 0.37(14.4)$ & $23.1 \pm 0.67(25.7)$ \\
\hline 20 & -1 & +1 & +1 & -1 & $11.1 \pm 1.09(6.6)$ & $13.9 \pm 1.36(10.1)$ & $24.9 \pm 2.44(18.2)$ \\
\hline 21 & -1 & -1 & +1 & +1 & $19.8 \pm 0.59(16.3)$ & $24.8 \pm 0.73(21.4)$ & $44.4 \pm 1.32(38.4)$ \\
\hline 22 & -1 & -1 & -1 & -1 & $13.0 \pm 0.21(12.5)$ & $16.3 \pm 0.26(15.1)$ & $29.1 \pm 0.47(27.1)$ \\
\hline 23 & +1 & -1 & +1 & -1 & $23.9 \pm 0.9(22.5)$ & $19.9 \pm 0.75(18.5)$ & $35.7 \pm 1.35(33.1)$ \\
\hline 24 & -1 & +1 & +1 & +1 & $18.2 \pm 0.68(18.5)$ & $22.8 \pm 0.85(23.5)$ & $40.7 \pm 1.53(42.1)$ \\
\hline 25 & 0 & 0 & 0 & -2 & $5.0 \pm 0.32(4.4)$ & $5.1 \pm 0.32(4.1)$ & $9.12 \pm 0.58(7.5)$ \\
\hline 26 & 0 & 0 & 0 & +2 & $15.1 \pm 1.07(17.0)$ & $15.2 \pm 1.07(16.6)$ & $27.1 \pm 1.93(29.9)$ \\
\hline 27 & -1 & +1 & -1 & -1 & $5.3 \pm 0.18(7.1)$ & $6.7 \pm 0.23(9.6)$ & $11.9 \pm 0.41(17.2)$ \\
\hline \multicolumn{5}{|c|}{$\begin{array}{l}\text { Optimized condition (predicted by } \\
\text { desirability function) }\end{array}$} & 28.2 & 23.7 & 42.3 \\
\hline \multicolumn{5}{|c|}{ Optimized condition (experimental data) } & $25.1 \pm 1.50$ & $20.9 \pm 1.25$ & $37.5 \pm 2.24$ \\
\hline
\end{tabular}

glucose yield (2.8 g/100g $\left.\mathrm{g}_{\text {ISF-D }}\right)$ was achieved in run $15(12 \%$ $\mathrm{w} / \mathrm{v}$ of solids loading, $55 \mathrm{~min}, 160{ }^{\circ} \mathrm{C}$ and $3.0 \% \mathrm{w} / \mathrm{v} \mathrm{H}_{2} \mathrm{SO}_{4}$ ). No residual glucose was observed in runs 4, 8, 10, 12, 17, 20, $21,23,24$ and $26\left(0.0 \mathrm{~g} / 100 \mathrm{~g}_{\text {ISF-D }}\right)$. In these cases, temperatures were in the range of $170-190{ }^{\circ} \mathrm{C}$, indicating that temperature has a high effect on glucose conversion, which was already observed by other investigators [30]. This fact is also confirmed by the maximal LA concentration that was obtained at a relatively higher $T$ of $180{ }^{\circ} \mathrm{C}$ while the lower concentration of LA was achieved at a lower $T$ of $170{ }^{\circ} \mathrm{C}$.

The maximum FA yield $\left(2.4 \mathrm{~g} / 100 \mathrm{~g}_{\text {ISF-D }}\right)$ was verified in trial 17 , and the lowest value was $0.9 \mathrm{~g} / 100 \mathrm{~g}_{\text {ISF-D }}$ in trial 25 . Comparing concentrations of LA and FA on a molar basis, it was observed that less FA was produced than the stoichiometric proportion. This same behavior was verified by Galletti et al. [31] when analyzing the production of LA with homogeneous acid catalysts in poplar sawdust, paper mill sludge, tobacco chops, wheat straw, and olive tree pruning, with $11.5 \mathrm{mEq}$ $\mathrm{HCl}$ and $83 \mathrm{mEq} \mathrm{H}_{2} \mathrm{SO}_{4}$, at $200{ }^{\circ} \mathrm{C}$ and $1 \mathrm{~h}$. Authors justify the smaller concentrations of FA regarding LA due to the possibility of reactions secondary to the process, such as the formation of HUs. The same phenomenon was observed by Fleig et al. [32] when converting rice husk into LA in a three-step process, being the last one (catalytic depolymerization of cellulose) run at $175{ }^{\circ} \mathrm{C}, 5.0 \% \mathrm{w} / \mathrm{v} \mathrm{H}_{2} \mathrm{SO}_{4}$ and $75 \mathrm{~min}$.

\section{Main Effects on the Statistical Analysis of LA Production}

The effects of $S, t, T$, and $A$, according to responses $C_{\mathrm{LA}}, Y_{\mathrm{LA}}$, and $E_{\mathrm{LA}}$, were investigated (Fig. 2). Regarding the solids loading, it was observed a negative effect for the first-order effect (or linear) of $Y_{\mathrm{LA}}$ and $E_{\mathrm{LA}}$ and positive regarding $C_{\mathrm{LA}}$, having high significance ( $p$ value of 0.0035 ) (Fig. 2a). In the quadratic 

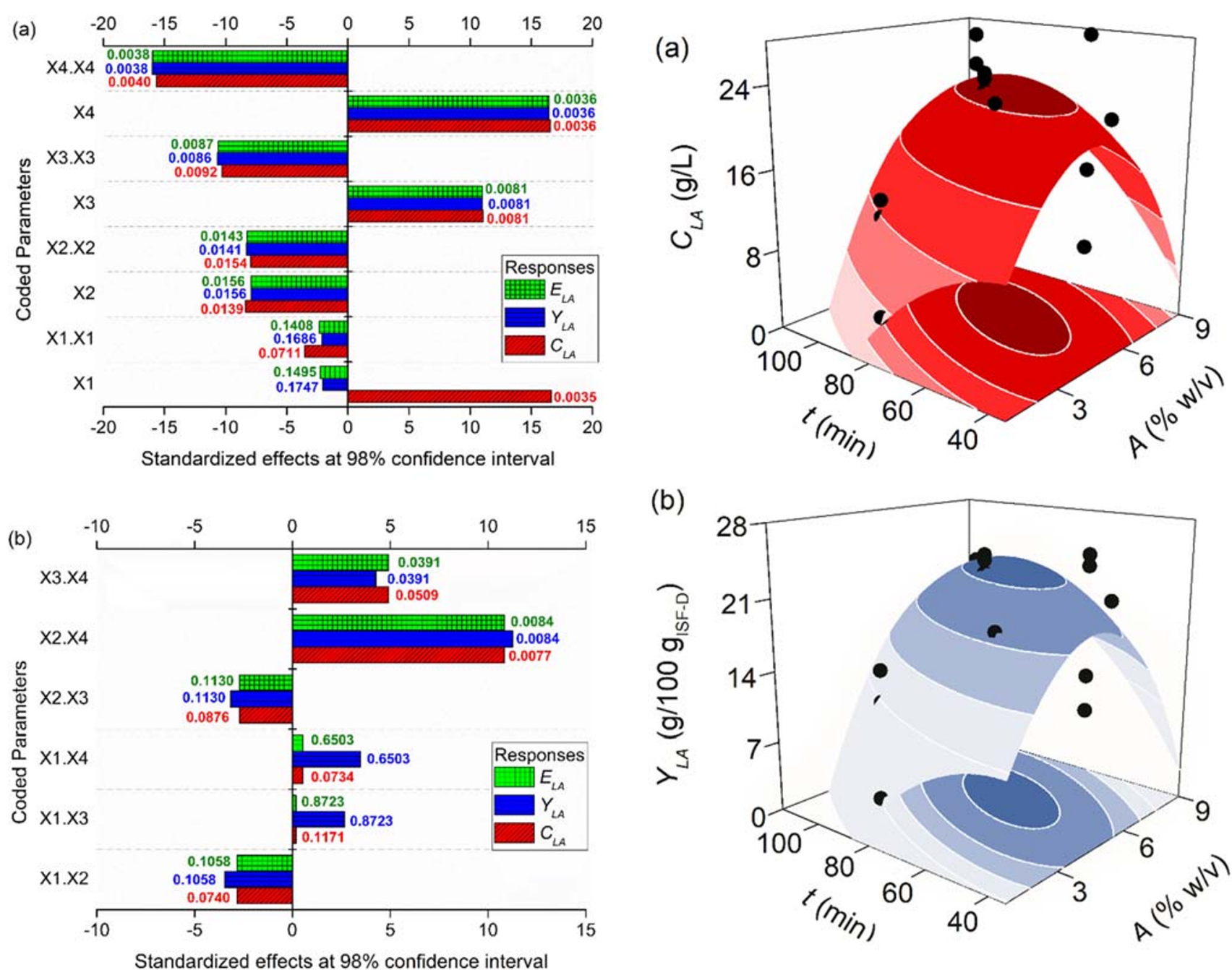

Fig. 2 Standardized effects at $98 \%$ confidence interval: a main and quadratic effects; b interaction effects. (X1): coded variable for $S$; (X2): coded variable for $t$; (X3): coded variable for $T$; (X4): coded variable for $A$

effect of this one (Fig. 2a) and in the interaction with reaction time (Fig. 2b), the effect was negative. The effect with interactions of temperature and concentration of acid is positive, while the effects of interactions between the factors are not significant for any response $(p$ value $>0.02)$ (Fig. $2 b)$. The solids loading has a slightly more pronounced effect when allied to reaction time than when compared to the other variables (Fig. 2b), which is evident by the results of Table 5. It is still possible to verify by Fig. 2 that solids loading is the variable with the least effect. This means that a higher solids loading would not result in higher amounts of cellulose decomposition. Kim et al. [33] also reported that the concentration of substrate had the least effect on the conversion of glucose to LA and FA.

When analyzing the reaction time, only its interaction with temperature has a positive effect on all responses (Fig. 2b), although not significant in the range evaluated. It is possible to notice from trials 4 and 17 (Table 5) that under the same

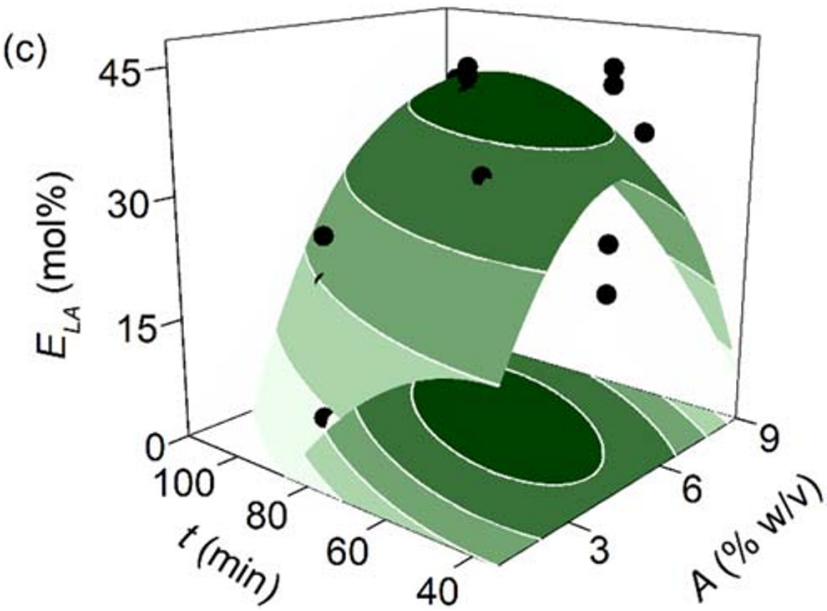

Fig. 3 Response surfaces for the effect of $t \times A$ (only significant interaction at $98 \%$ confidence level) for a $C_{\mathrm{LA}}, \mathbf{b} Y_{\mathrm{LA}}$, and $\mathbf{c} E_{\mathrm{LA}}$. Filled circles represent experimental data

operating conditions $\left(180{ }^{\circ} \mathrm{C}, 7.0 \% \mathrm{w} / \mathrm{v} \mathrm{H}_{2} \mathrm{SO}_{4}\right.$ and $12 \%$ solids loading), a reaction time ranging from 55 to $95 \mathrm{~min}$ does not seem to impact in the response, with only $1 \mathrm{~g} / \mathrm{L}$ of LA more being produced (which is insignificant considering 
the standard deviation). However, the only significant interaction term is the interaction of reaction time and acid concentration ( $p$ value of 0.0077 for $C_{\mathrm{LA}}$ and of 0.0084 for $Y_{\mathrm{LA}}$ and $\left.E_{\mathrm{LA}}\right)$ (Fig. 2b). The combination of these interactions seems to generate a response similar to a parabola, indicating the presence of optimal conditions.

It is possible to analyze by the response surfaces (Fig. 3) that reaction times higher than $90 \mathrm{~min}$ associated to low concentrations of acid $(<3.0 \% \mathrm{w} / \mathrm{v})$ have no positive influence for any of the responses, indicating that for LA formation it is necessary the use of concentrations of acid higher than $3.0 \%$ $\mathrm{w} / \mathrm{v}$. When reaction times between 60 and $80 \mathrm{~min}$ and high concentrations of acid (5.0-7.0\% w/v) are combined, it may be seen from Fig. 3a-c that it is possible to reach a $C_{\mathrm{LA}}$ near $25.1 \mathrm{~g} / \mathrm{L}$ (Fig. 3a) equivalent to a $Y_{\mathrm{LA}}$ of $20.9 \mathrm{~g} / 100 \mathrm{~g}_{\text {ISF-D }}$ (Fig. $3 \mathrm{~b}$ ) and an $E_{\mathrm{LA}}$ of $37.5 \mathrm{~mol} \%$ (Fig. 3c). Jeong [34] stated that reaction time impacts positively on LA yields, although the author only analyzes reaction times below $50 \mathrm{~min}$. However, the use of longer reaction times favors the formation of HUs, thus causing a decrease in the yield of LA [35, 36], and this should be accounted for in process development.

Regarding temperature, the first-order effect has a positive effect on all responses (Fig. 2a), as in the interaction of temperature with acid concentration (Fig. 2b). However, the quadratic term has a negative effect (Fig. 2a). The $p$ value is significant both for first and quadratic effects for all responses (Fig. 2a). This occurs because the temperature has an important effect in the production of LA facilitating the hydrolysis of cellulose by breaking its rigid structure, living it susceptible to the formation of 5-HMF and in the sequence of LA and FA [37].

Analyzing the responses $C_{\mathrm{LA}}, Y_{\mathrm{LA}}$, and $E_{\mathrm{LA}}$, those have their higher values when the temperature of $180^{\circ} \mathrm{C}$ was used. On the other hand, a decrease in the analyzed responses was observed when using $190^{\circ} \mathrm{C}$, reaching $15.5 \mathrm{~g} / \mathrm{L}$ of LA, which is possibly correlated with the simultaneous formation of $\mathrm{HUs}$ and poorer selectivity. Park et al. [38] also reported an optimal temperature of $180{ }^{\circ} \mathrm{C}$, for the production of LA from Gracilaria verrucosa. Also, Kim et al. [33] found $181{ }^{\circ} \mathrm{C}$ as the optimal temperature in the production of LA from glucose. Generally, when considering the operating conditions applied to hydrolysis, the most significant of them is the temperature, influencing drastically on the hydrolysis yields. Earlier studies proved that the temperature applied during hydrolysis is important to modify the rigid structure of lignocellulosic materials since the rate of hydrolysis can be increased when using higher temperatures [30].

The most significant effect, the acid concentration ( $p$ value of 0.0036), demonstrated also to be the one with the highest effect for all responses (Fig. 2a). Acid catalysis is considered one of the most important variables in LA synthesis. The firstorder term has a positive effect, while the quadratic term has a negative effect on all responses (Fig. 2a). This indicates that for the concentration of acid the responses have a maximum point (Fig. 3a-c); the same behavior was verified when the production of LA from rice husk was analyzed [28]. In other words, the axial points used for the concentration of acid, 1.0 and $9.0 \% \mathrm{w} / \mathrm{v} \mathrm{H}_{2} \mathrm{SO}_{4}$ (trials 25 and 26; Table 5) have low concentrations of LA, 5.0 and $15.1 \mathrm{~g} / \mathrm{L}$ respectively, indicating that those extremes that were analyzed do not favor the production of LA. Analogously with temperature, the concentration of acid was also positively correlated with the responses analyzed for LA: the higher the concentration of sulfuric acid was, the greater were the LA responses (with increased rates of carbohydrate hydrolysis to organic acids). The same behavior was verified by Fang and Hanna [39]: even though they worked with a concentration of $\mathrm{H}_{2} \mathrm{SO}_{4}$ up to $8 \%$, they did not find a decrease in the yield at a high concentration of catalyst.

\section{Reliability Analysis of the Statistical Model}

The experimentally obtained values (Table 5) were analyzed through multiple regression. The adequacy of the developed models was analyzed by means of the analysis of variance (ANOVA) for responses $C_{\mathrm{LA}}, Y_{\mathrm{LA}}$ and $E_{\mathrm{LA}}$ (Supplementary Information-S3). Coefficients of the surrogate models were considered significant if the $p$ value was less than 0.02 . Having a low $p$ value $(p<0.02)$ implies that the respective coefficient was statistically significant at a confidence level of $98 \%$, meaning that the probability of noise caused in the correlation between one factor and the response is inferior to 0.02 . Analyzing responses $C_{\mathrm{LA}}, Y_{\mathrm{LA}}$, and $E_{\mathrm{LA}}$, the linear coefficient of $T\left(\alpha_{3}\right)$; the three quadratic coefficients $t, T$, and $A$ $\left(\alpha_{22}, \alpha_{33}, \alpha_{44}\right)$; and the interaction coefficient $t \times A\left(\alpha_{24}\right)$ were determined as having significance at the confidence level of 98\% (Supplementary Information-S3). According to this analysis, $t, T$, and $A$ were significant, indicating that they have a high influence in the responses analyzed during the conversion of LA.

For $C_{\mathrm{LA}}$, according to ANOVA (Supplementary Information-S3), the model finds the condition of adjustment for the $F$ test. It may be observed that the value of the $F$ test calculated for regression analysis (6.103) is higher than the tabulated value (3.401), satisfying the test. The model also has a good adjustment, because the value of the $F$ test calculated is 16.934 , which is smaller than the tabulated value of 49.398. For $Y_{\mathrm{LA}}$ and $E_{\mathrm{LA}}$, the test is also satisfied: 3.964 and 3.874 for $F$ test for regression analysis and 20.039 and 20.409 for the adjustment of the model, respectively.

The fit of regression models for each response $\left(C_{\mathrm{LA}}, Y_{\mathrm{LA}}\right.$, and $\left.E_{\mathrm{LA}}\right)$ was verified by the coefficient of determination $\left(R^{2}\right)$. Values of $0.876,0.822$, and 0.818 were obtained for $C_{\mathrm{LA}}, Y_{\mathrm{LA}}$, and $E_{\mathrm{LA}}$, respectively. These results indicate that only $12.4 \%$, $17.8 \%$, and $18.2 \%$ of the total variation could not be explained by the model due to high non-linearity between the studied variables. This is confirmed when analyzing the proximity 
between most of the experimental values and predicted by the model (values between parentheses in Table 5). The value for the relative error of the experimental and predicted values for $C_{\mathrm{LA}}$ was $14.8 \%$, whereas for $Y_{\mathrm{LA}}$, it was $16.3 \%$, and for $E_{\mathrm{LA}}$, it was $16.5 \%$.

\section{Multi-response Optimization for LA Production}

Analyzing each response individually, it was found that for $C_{\mathrm{LA}}$, the maximum experimental value was $28.4 \mathrm{~g} / \mathrm{L}$ (trial 17-Table 5) besides trial 4 which has a value of $27.3 \mathrm{~g} / \mathrm{L}$. On the other hand, for $Y_{\mathrm{LA}}$ and $E_{\mathrm{LA}}$, the maximum values are found in different trials. For $Y_{\mathrm{LA}}$ is the maximum value of $24.9 \mathrm{~g} / 100 \mathrm{~g}_{\text {ISF-D }}$ (trial 8-Table 5), besides trials 7 and 21 that have close values (24.4 and $24.8 \mathrm{~g} / 100 \mathrm{~g}_{\text {ISF-D }}$, respectively). Analogously, for $E_{\mathrm{LA}}$, the maximum value was $44.7 \mathrm{~mol} \%$ (trial 8-Table 5), besides trials 7 and 21 that have close values (43.6 and $44.4 \mathrm{~mol} \%$, respectively). The desirability function $(D)$ approach in the case of the nominal-the-best was used to incorporate the multiple responses of LA production into a single response in the form of the composite desirability function. Supplementary Information - S4 shows the results of the predicted responses after random shuffles at each level of each factor holding all other factors constant.
In this way, the optimization allowed the elaboration of profiles for the predicted values of responses and the functions of desirability (Eq. 5). The maximum value of desirability $(D)$ for the optimized process was 0.953 (Fig. 4). The optimized condition of ACC that satisfies simultaneously the responses $C_{\mathrm{LA}}, Y_{\mathrm{LA}}$, and $E_{\mathrm{LA}}$, was found to be $12.0 \% \mathrm{w} / \mathrm{v}$ of solids loading, $75 \mathrm{~min}, 180{ }^{\circ} \mathrm{C}$, and $7.0 \% \mathrm{w} / \mathrm{v}_{2} \mathrm{SO}_{4}$. This resulted in the following predicted values: $28.2 \mathrm{~g} / \mathrm{L}$ of $C_{\mathrm{LA}}, 23.7 \mathrm{~g} /$ $100 \mathrm{~g}_{\mathrm{ISF}-\mathrm{D}}$ of $Y_{\mathrm{LA}}$, and $42.3 \mathrm{~mol} \%$ of $E_{\mathrm{LA}}$. Experiments in triplicate were made in the optimized condition of operation and obtained a $C_{\mathrm{LA}}$ of $25.1 \mathrm{~g} / \mathrm{L}$, a $Y_{\mathrm{LA}}$ of $20.9 \mathrm{~g} / 100 \mathrm{~g}_{\mathrm{ISF}-\mathrm{D}}$, and an $E_{\mathrm{LA}}$ of $37.5 \mathrm{~mol} \%$. This indicates an error of at least $10.9 \%$ between the predicted and observed values for $C_{\mathrm{LA}}, 11.8 \%$ for $Y_{\mathrm{LA}}$, and $11.3 \mathrm{~mol} \%$ for $E_{\mathrm{LA}}$. Similarly, Park et al. [38] found an optimized operating condition in $180{ }^{\circ} \mathrm{C}, 10 \%$ of biomass, $0.5 \mathrm{M}$ of methanesulfonic acid and $20 \mathrm{~min}$ of reaction for the production of LA from Gracilaria verrucosa. Those authors obtained a yield of $22.0 \%$ based on biomass weight. Kang et al. [35] used a batch reactor to produce LA from marine biomass Gelidium amansii. They obtained, in the optimized condition, a yield of $42.8 \%$ at $180{ }^{\circ} \mathrm{C}, 3 \% \mathrm{w} / \mathrm{w} \mathrm{H}_{2} \mathrm{SO}_{4}$ and $48 \mathrm{~min}$. Ramli and Amin [36] found an optimized condition at $154.5^{\circ} \mathrm{C}, 3.7 \mathrm{~h}, 0.18 \mathrm{~g}$ starting from oil palm fronds and [SMIM] $\left[\mathrm{FeCl}_{4}\right]$ as catalyst achieving $24.8 \%$ of LA yield.
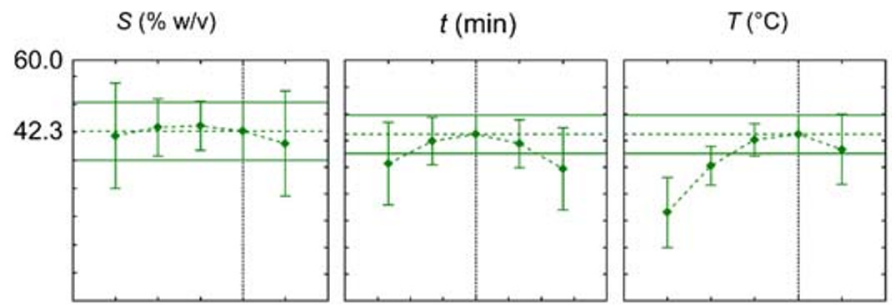

$A(\% \mathrm{w} / \mathrm{v})$
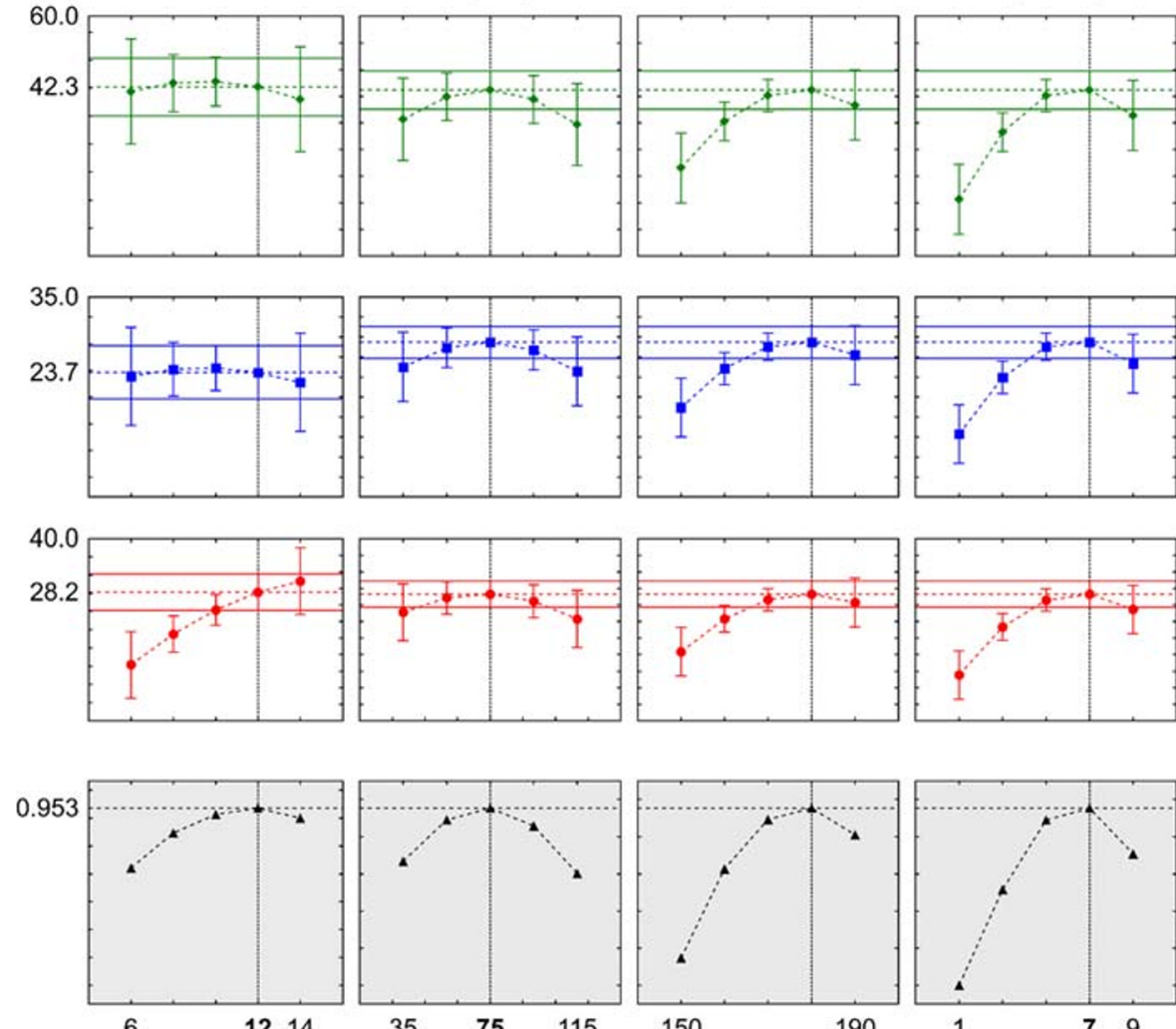

6
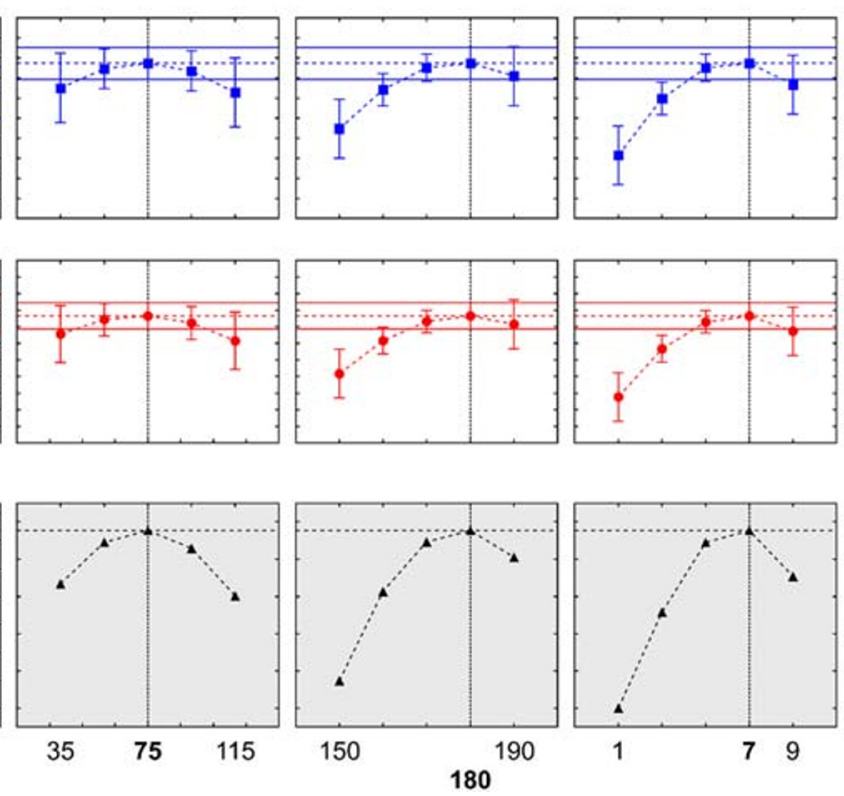
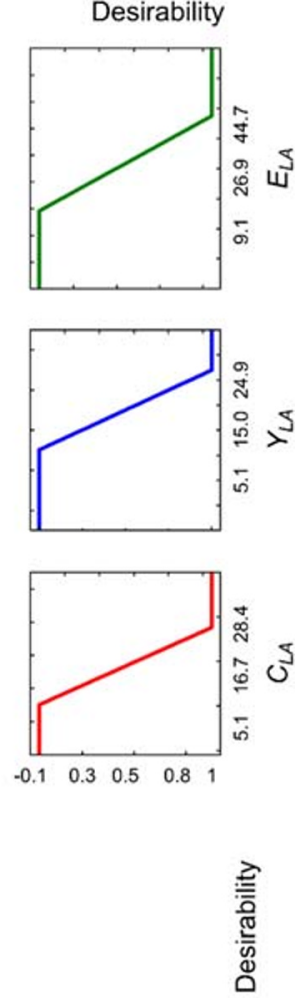

Fig. 4 Predicted response profiles $\left(C_{\mathrm{LA}}, Y_{\mathrm{LA}}\right.$, and $\left.E_{\mathrm{LA}}\right)$ and the desirability function when considering a $98 \%$ confidence level $(p<0.02$, horizontal continuous line) by analyzing $S, t, T$, and $A$. Vertical dotted lines indicate values below optimal values 
Fig. 5 Scheme showing the six scenarios of the multi-step strategy for SCB biorefining to LA, FA, and HUs (dry basis)

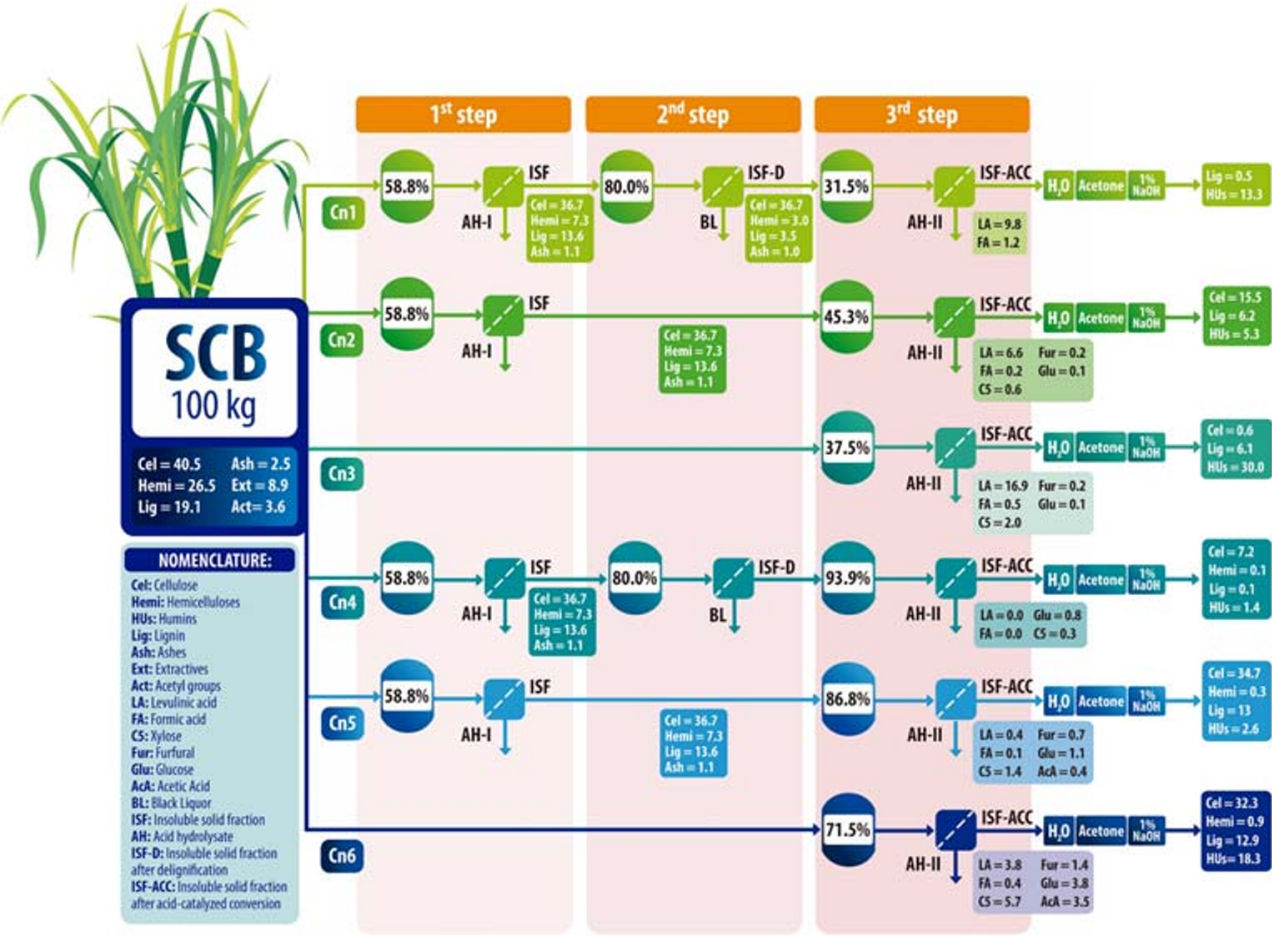

Pradipta et al. [10] also proved that multiple-stage acid-catalyzed conversion of carbohydrates into LA is crucial to increase the LA yield. Nevertheless, the researchers do not consider a DL step. This process design is valid if a solvent is used for lignin and hemicelluloses break up. In this sense, the authors used $\mathrm{HCl}$, which can also remove lignin.

After considering process optimization, it is necessary to analyze and provide the efficiency of the biomass fractionation in a multi-step process for LA production. Thus, the following session discusses the evaluation of six conceptual scenarios (ranging from one to three steps) in the process of LA production.

\section{Multi-step Conceptual Scenarios for LA Production}

Fractionation of SCB was analyzed through six conceptual scenarios as described in "Multi-step Strategies for Production of LA and HUs" and based on the concepts of integrated use of biomass. The results are reported in Fig. 5 considering $100 \mathrm{~kg} \mathrm{SCB}$ (dry basis). $\mathrm{Cn} 1$ and $\mathrm{Cn} 4$ consist of SCB being submitted to three steps of biorefining: for Cn1, PT is followed by DL and then ACC (corresponding to the optimized values found in this study), and for $\mathrm{Cn} 4$, PT is followed by DL, and then one step on the same operating conditions of ACC but only involving a hydrothermal conversion (no $\mathrm{H}_{2} \mathrm{SO}_{4}$ added).

The first step of fractionation had a recovery (ISF) of $58.8 \mathrm{~kg}$ indicating that $41.2 \mathrm{~kg}$ was solubilized. ISF consists mainly of $36.7 \mathrm{~kg}$ of cellulose $(90.8 \%$ recovery of cellulose from SCB), $13.6 \mathrm{~kg}$ of lignin ( $72.1 \%$ recovery of cellulose from SCB), and $1.1 \mathrm{~kg}$ of ash. This fraction was then submitted to DL, which resulted in the removal of $91.3 \%$ of ash and partial solubilization of lignin, nearly $82.0 \%$ of the raw SCB. ISF-D, a solid resulting from DL, had a mass of $44.2 \mathrm{~kg}$, equivalent to $47.0 \%$ of the initial SCB. These processes increase the accessibility to cellulose (78\% of cellulose in ISFD; Table 3) with $90.8 \%$ of cellulose recovery regarding the cellulose content in SCB, favoring the production of LA. Then, the third step was executed to hydrolyze the remaining cellulose to produce LA. After ACC, the remaining solid was separated by filtration, resulting in $13.8 \mathrm{~kg}$ for $\mathrm{Cn} 1$ and $43.0 \mathrm{~kg}$ for $\mathrm{Cn} 4$, which was equivalent to $31.5 \%$ and $93.3 \%$ of ISF-D for $\mathrm{Cn} 1$ and $\mathrm{Cn} 4$, respectively. After the extraction process according to Hoang et al. (2015) [23], nearly $13.3 \mathrm{~kg}$ for $\mathrm{Cn} 1$ and $7.1 \mathrm{~kg}$ for $\mathrm{Cn} 4$ of HUs were recovered. For $\mathrm{Cn} 1$, the amount of cellulose in the solid waste was null (complete conversion), and in $\mathrm{Cn} 4$, it was $35.3 \mathrm{~kg}$.

Concentrations of LA and FA were high when using $\mathrm{H}_{2} \mathrm{SO}_{4}$ in the last step $(\mathrm{Cn} 1)$ and indetectable when considering the hydrothermal process $(\mathrm{Cn} 4)$. In scenario $\mathrm{Cn} 1$, the mass of LA obtained after the third step was $9.8 \mathrm{~kg}$, with equivalent values of $Y_{\mathrm{LA}}$ and $E_{\mathrm{LA}}$ of $21.5 \mathrm{~g} / 100 \mathrm{~g}_{\mathrm{ISF}-\mathrm{D}}$ and $38.5 \mathrm{~mol} \%$, and the mass of FA was $1.2 \mathrm{~kg}$. LA yields regarding the initial raw material represent $24.3 \%$ of the cellulose in SCB, $9.8 \%$ of raw SCB, and $34.0 \mathrm{~mol} \%$ based on theoretical yield from cellulose in SCB. The concentration of LA was $20.9 \mathrm{~g} / \mathrm{L}$. After analysis of results of $\mathrm{Cn} 1$ and $\mathrm{Cn} 4$, it becomes evident that the use of a strong acid catalyst in the third step is fundamental for the production of LA: when no strong acid is present, there is no production of LA 
and the amount of cellulose in the solid waste is preserved, thus making $\mathrm{Cn} 4$ unfeasible.

Scenarios $\mathrm{Cn} 2$ and $\mathrm{Cn} 5$ were comprised of two steps: in the case of $\mathrm{Cn} 2$, PT was followed by ACC (considering the optimized conditions described in this work: $180{ }^{\circ} \mathrm{C}, 75 \mathrm{~min}$, $12.0 \% \mathrm{w} / \mathrm{v}$ solids loading and $7.0 \% \mathrm{w} / \mathrm{v} \mathrm{H}_{2} \mathrm{SO}_{4}$ ), whereas for $\mathrm{Cn} 5$, PT was followed by a step under the same operating conditions of ACC but involving a hydrothermal. After ACC, the solid waste was separated by filtration, resulting in $27.1 \mathrm{~kg}$ for $\mathrm{Cn} 2$ and $50.6 \mathrm{~kg}$ for $\mathrm{Cn} 5$, which is equivalent to $45.3 \%$ and $86.8 \%$ of ISF for $\mathrm{Cn} 2$ and $\mathrm{Cn} 5$, respectively. After the extraction process was performed on the solid residue of ACC, $5.3 \mathrm{~kg}$ of HUs were obtained in $\mathrm{Cn} 2$ and $2.6 \mathrm{~kg}$ in $\mathrm{Cn} 5$. In $\mathrm{Cn} 2$, the amount of cellulose in the solid waste was $15.5 \mathrm{~kg}$ ( $38.3 \%$ recovery of cellulose from SCB), and in $\mathrm{Cn} 5$, it was $34.7 \mathrm{~kg}(85.6 \%$ recovery of cellulose from $\mathrm{SCB})$. The concentrations of LA and FA after the ACC step were considered as relatively high when using $\mathrm{H}_{2} \mathrm{SO}_{4}(\mathrm{Cn} 2)$ and low with the hydrothermal conversion ( $\mathrm{Cn} 5$ ). It was possible to obtain from ISF $0.2 \mathrm{~kg}$ of FA in $\mathrm{Cn} 2$ and $0.1 \mathrm{~kg}$ in $\mathrm{Cn} 5$. The mass of LA obtained after the ACC step was of $6.6 \mathrm{~kg}$ in $\mathrm{Cn} 2$ and $0.4 \mathrm{~kg}$ in $\mathrm{Cn} 5$, with equivalent values of $Y_{\mathrm{LA}}$ of 10.9 and $0.7 \mathrm{~g} / 100 \mathrm{~g}_{\mathrm{ISF}}$ and $E_{\mathrm{LA}}$ of 24.5 and $1.6 \mathrm{~mol} \%$, respectively. LA yields regarding the initial raw material represent $16.2 \%$ and $1.1 \%$ of cellulose in SCB for $\mathrm{Cn} 2$ and $\mathrm{Cn} 5$, respectively; $6.6 \%$ and $0.4 \%$ of SCB; and $22.6 \mathrm{~mol} \%$ and $1.5 \mathrm{~mol} \%$ based on theoretical yield from cellulose content of SCB. The concentration of LA was $11.2 \mathrm{~g} / \mathrm{L}$ and $0.7 \mathrm{~g} / \mathrm{L}$ for $\mathrm{Cn} 2$ and $\mathrm{Cn} 5$, respectively. Scenarios $\mathrm{Cn} 2$ and $\mathrm{Cn} 5$ indicate that the use of acid catalysis favorable for the production of LA. Regarding the decomposition of cellulose, $\mathrm{Cn} 2 \mathrm{kept} 15.5 \mathrm{~kg}$ of this fraction, while Cn5 kept $34.7 \mathrm{~kg}$, indicating a small yield when compared with $\mathrm{Cn} 1$ and $\mathrm{Cn} 4$ (0.0 and $35.3 \mathrm{~kg}$, respectively). Therefore, when comparing $\mathrm{Cn} 1$ and $\mathrm{Cn} 2$, it becomes evident that the DL step (present on $\mathrm{Cn} 1$ ) increases the concentrations of LA and FA.

Literature reports other results for biomass processing in two steps. Kang et al. [35] studied the optimized conditions for LA production from Gelidium amansii using a two-step treatment. Those authors reached a maximum yield of $42.8 \%$ as a function of the initial amount of biomass at $180{ }^{\circ} \mathrm{C}, 3 \% \mathrm{w} /$ $\mathrm{w}$ of sulfuric acid, and $48 \mathrm{~min}$ of reaction. On the other hand, Wang et al. [40] analyzed a two-step process to produce furfural and LA using a hydrothermal treatment combined with a solid acid catalyst in SCB. After the second step, they reached a yield of $62.1 \%$ at $180{ }^{\circ} \mathrm{C}$ and $3 \mathrm{~h}$ of reaction. The high yield found by the authors may be due to the use of a solid catalyst, which keeps the cellulose and hemicelluloses in the first step. Besides, the authors do not consider the fraction of hemicelluloses in the calculation of the yield, although LA may also be produced from it [41]. Authors also do not report about the formation of HUs, which is related to the selectivity of the solid acid catalyst. Nevertheless, the use of heterogeneous catalysts in SCB conversion is a cumbersome task: their catalytic sites may be deactivated by the formation of HUs [14] and its recovery is not reported.

Scenarios Cn3 and Cn6 consisted of a single step of ACC. $\mathrm{Cn} 3$ used the optimized operating conditions of ACC, whereas $\mathrm{Cn} 6$ used the same operating conditions but with no addition of $\mathrm{H}_{2} \mathrm{SO}_{4}$. After the reaction, the solid residue was separated by filtration, resulting in $36.8 \mathrm{~kg}$ for $\mathrm{Cn} 3$ and $64.4 \mathrm{~kg}$ for Cn6, equivalent to $37.5 \%$ and $71.5 \%$ of the raw SCB for Cn3 and $\mathrm{Cn} 6$, respectively. After the extraction performed on this solid residue, $30 \mathrm{~kg}$ in $\mathrm{Cn} 3$ and $18.3 \mathrm{~kg}$ in $\mathrm{Cn} 6$ of HUs were obtained. For $\mathrm{Cn} 3$, the amount of cellulose in the solid residue was $0.6 \mathrm{~kg}$ ( $1.6 \%$ recovery of cellulose from SCB), and in $\mathrm{Cn} 6$, it was $32.3 \mathrm{~kg}(79.9 \%$ recovery of cellulose from SCB). Concentrations of LA and FA were higher using when using acid in ACC ( $\mathrm{Cn} 3)$ than when using only water $(\mathrm{Cn} 6)$. This way, it was obtained $0.5 \mathrm{~kg}$ of FA in $\mathrm{Cn} 3$ and $0.4 \mathrm{~kg}$ of FA in Cn6 for each $100 \mathrm{~kg}$ of SCB. The mass of LA obtained was $16.9 \mathrm{~kg}$ and $3.8 \mathrm{~kg}$ for $\mathrm{Cn} 3$ and $\mathrm{Cn} 6$, respectively, with equivalent values of $Y_{\mathrm{LA}}$ of 17.0 and $3.9 \mathrm{~g} / 100 \mathrm{~g}_{\mathrm{SCB}}$. LA yields regarding the initial raw material represented $41.8 \%$ and $9.3 \%$ of cellulose in SCB for $\mathrm{Cn} 3$ and $\mathrm{Cn} 6$, respectively; $16.9 \%$ and $3.8 \%$ of raw SCB; and $58.4 \mathrm{~mol} \%$ and $13.0 \mathrm{~mol} \%$ based on the theoretical yield from cellulose on SCB. The concentration of LA was $16.9 \mathrm{~g} / \mathrm{L}$ and $3.8 \mathrm{~g} / \mathrm{L}$ for $\mathrm{Cn} 3$ and $\mathrm{Cn} 6$, respectively. It was possible to observe that, as in the previously discussed scenarios, the use of $\mathrm{H}_{2} \mathrm{SO}_{4}$ increases the yield of LA: $\mathrm{Cn} 3$ produced a higher concentration of LA (16.9 g/L) than Cn6 $(3.8 \mathrm{~g} / \mathrm{L})$. Nevertheless, the formation of HUs was also higher (30.0 kg in $\mathrm{Cn} 3$ and $18.3 \mathrm{~kg}$ in $\mathrm{Cn} 6$ ).

Regarding $\mathrm{Cn} 3$ and $\mathrm{Cn} 6$, it is also possible to attribute the high formation of HUs with the presence of hemicelluloses, an observation that was already reported in the literature. Chamnankid et al. [41] demonstrated the synthesis of LA starting from xylose under hot-compressed water using as catalyst an alkaline-treated zeolite. The treatment created new strong acid sites over the surface of the zeolite and improved the LA yield. The maximum LA yield was $30.0 \%$ after $3 \mathrm{~h}$ of reaction. Although high reaction temperatures $\left(190^{\circ} \mathrm{C}\right)$ led to high conversion, they also led to an increased formation of by-products. The increase of temperature from 170 to $190{ }^{\circ} \mathrm{C}$ reduced the LA yield by $8.0 \%$, while the furfural yield increased from 28.0 to $30.0 \%$. The authors reported that under higher temperatures the formation of HUs was increased due to the dehydration of xylose to furfural. It was proposed by the authors that xylose was mostly converted into intermediaries that, eventually, were transformed in desirable products with the formation of insignificant amounts of HUs under $130{ }^{\circ} \mathrm{C}$. The catalytic conversion of hemicellulosic sugars from biomass to produce LA was conducted by Jeong et al. [42] using zeolite $\mathrm{Y}$ modified via $\mathrm{NaOH}$ treatment in different concentrations. The best LA yield was $4.6 \mathrm{~g} / 100 \mathrm{~g}_{\text {biomass }}$ (conversion of pentoses to LA: $42.7 \%$, based on theoretical yield) of the 
liquid hydrolyzed when using the zeolite treated with $0.25 \mathrm{M}$ $\mathrm{NaOH}$, at $190^{\circ} \mathrm{C}$ and $180 \mathrm{~min}$. The authors reported that at $210^{\circ} \mathrm{C}$, the yield of LA decreased to $3.9 \mathrm{~g} / 100 \mathrm{~g}_{\text {biomass }}$ due to a large hydrolysis rate, which increased the rate of condensation reactions that produce HUs.

It was evident that the higher concentrations of LA and FA were obtained in scenarios that use $\mathrm{H}_{2} \mathrm{SO}_{4}$ in $\mathrm{ACC}(\mathrm{Cn} 1, \mathrm{Cn} 2$, and $\mathrm{Cn} 3$ ) (Fig. 5). It was also observed that the LA concentration was higher in scenario $\mathrm{Cn} 1$ than in $\mathrm{Cn} 2$. This result was attributed to the high accessibility of cellulose after the removal lignin via DL, which is a step available only in scenario $\mathrm{Cn} 1$. Analyzing the three scenarios with hydrothermal conversion ( $\mathrm{Cn} 4, \mathrm{Cn} 5$, and $\mathrm{Cn} 6$, no $\mathrm{H}_{2} \mathrm{SO}_{4}$ added), it was observed that $\mathrm{Cn} 6$ (1 step) has the higher concentrations of LA when compared with $\mathrm{Cn} 5$ ( 2 steps) and $\mathrm{Cn} 4$ (three steps). This occurs because hemicelluloses contain acetyl groups which are easily hydrolyzed by water at high temperature [43]. The product of this hydrolysis, acetic acid, though at low concentrations, increases the oxidizing strength of the medium, thus leading to a small yield of LA.

Allied with the process, it is also possible to analyze the formation of HUs. Although $\mathrm{Cn} 3$ with a single step of ACC produced considerable amounts of LA $(16.9 \mathrm{~kg})$, there was also the abundant simultaneous formation of HUs, $30.0 \mathrm{~kg}$ - the greatest amount found on the different scenarios studied. This may be explained by the fact that the hemicelluloses present on SCB become potential sources for the formation of HUs. As in $\mathrm{Cn} 1$, those fractions were completely removed, the formation of HUs in $\mathrm{Cn} 1(13.3 \mathrm{~kg})$ is smaller than in $\mathrm{Cn} 3$. Thus, it becomes evident that a high yield of LA is also related to an increased yield of HUs. Therefore, thinking of biorefinery strategies and the need to provide uses for any by-product of biomass fractionation, a better comprehension of the molecular structure of HUs is necessary.

\section{Analysis of FTIR of Solid Residue from the Evaluation of the Conceptual Scenarios}

The FTIR spectra of SCB and HUs of the different conceptual scenarios are presented in Fig. 6. The main stretching range regarding the presence of groups hydroxyl (bonds $\mathrm{O}-\mathrm{H}$ ) is reported in a wave number between 3422 and $3410 \mathrm{~cm}^{-1}$ and in $2880 \mathrm{~cm}^{-1}$ [13]. On the other hand, the weak contributions corresponding to aliphatic and aromatic bands between 3000 and $2900 \mathrm{~cm}^{-1}$ and near $2850 \mathrm{~cm}^{-1}$ correspond to the bending and stretching of $\mathrm{C}-\mathrm{H}$, as well as the vibration of the aromatic ring, from residual lignin, respectively [44].

Although the region of the spectrum encompasses the band with wave number from 4000 to $500 \mathrm{~cm}^{-1}$, the region of the fingerprint area from 1800 to $500 \mathrm{~cm}^{-1}$ is generally the one with more interest, because it has most of the spectral information regarding the molecular structure. Similar observations were made by Acquah et al. [44]. The spectra of HUs

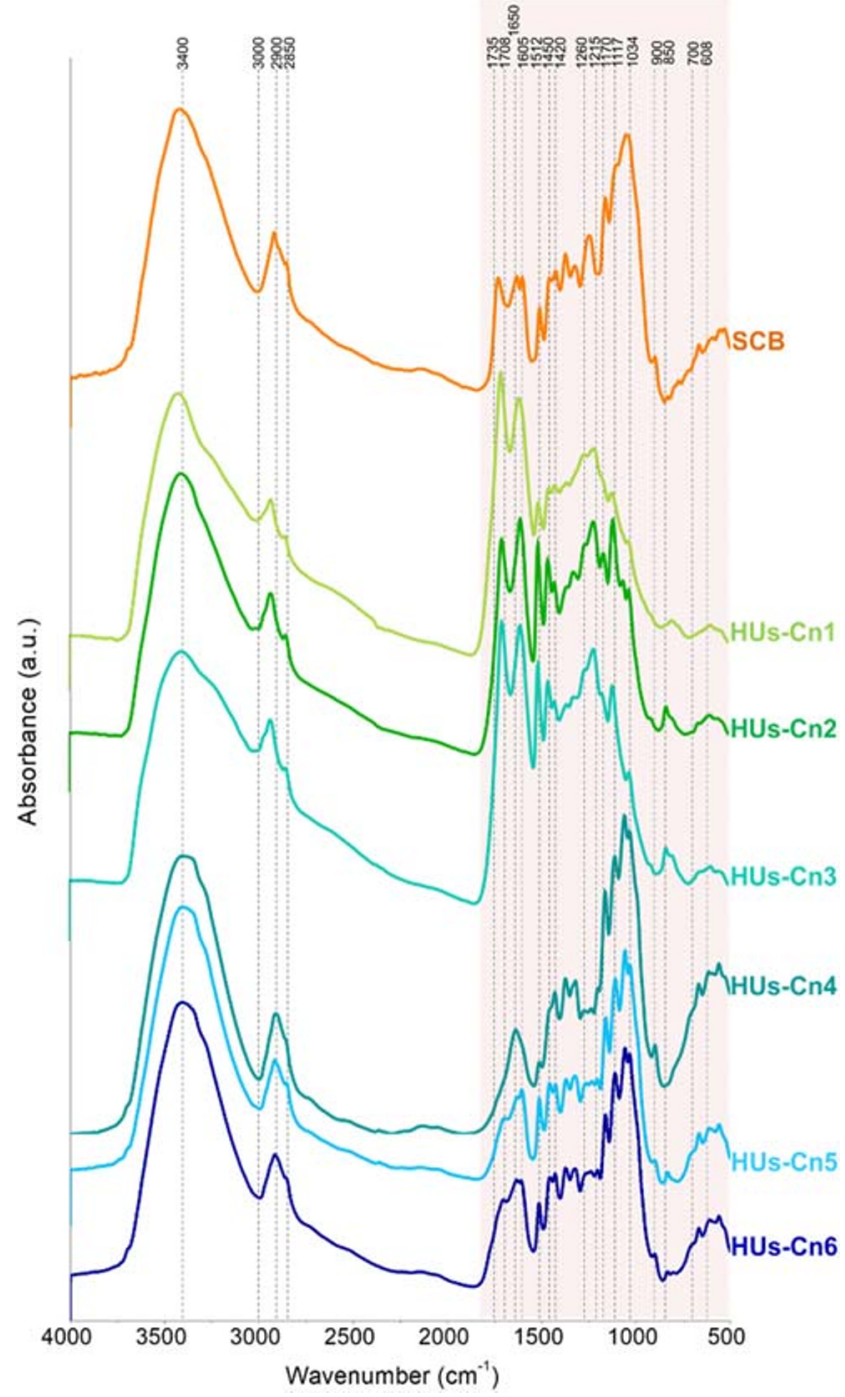

Fig. 6 FTIR spectra of sugarcane bagasse (SCB) and HUs from scenarios $\mathrm{Cn} 1, \mathrm{Cn} 2, \mathrm{Cn} 3, \mathrm{Cn} 4, \mathrm{Cn} 5$, and $\mathrm{Cn} 6$

of scenarios $\mathrm{Cn} 1, \mathrm{Cn} 2$, and $\mathrm{Cn} 3$ (HUs-Cn1, HUs-Cn2, and HUs-Cn3, respectively) (Fig. 5) had absorption patterns very similar when compared with the ones reported in the literature. The band in $1735 \mathrm{~cm}^{-1}$, which is a characteristic band of raw $\mathrm{SCB}$, was strongly reduced in HUs-Cn4, HUs-Cn5, and HUsCn6 (Fig. 6). On the other hand, the bands between 1800 and $1000 \mathrm{~cm}^{-1}$ significantly increase from SCB to HUs.

The oxygenated functional groups may also be observed from the spectra (Fig. 6). The peak between 1708 and $1697 \mathrm{~cm}^{-1}$, for HUs-Cn1, HUs-Cn2, HUs-Cn3, HUs-Cn5, and HUs-Cn6, was attributed to the stretching of $\mathrm{C}=\mathrm{O}$ [23], and its strong intensity suggests abundant aldehydes, ketones, and carboxyl groups [45]. Observing the presence of these organic functions is in accordance with the chemical structure of humins already suggested by other investigators [46]. As a relevant characteristic, spectra of HUs-Cn4, HUs-Cn5, and HUs-Cn6 (Fig. 6) clearly showed the presence of a furanyl 
structure [47] that was not observed in HUs-Cn1, HUs-Cn2, and HUs-Cn3, denoting that the conversion process involving the $\mathrm{ACC}$ suppresses the interaction $\mathrm{C}=\mathrm{C}$ or $\mathrm{C}=\mathrm{O}$. The peaks between 1612 and $1605 \mathrm{~cm}^{-1}$ and between 1520 and $1512 \mathrm{~cm}^{-1}$ were attributed to the stretch $\mathrm{C}-\mathrm{C}$ of the furan ring [23], which corresponds to poly-substituted furans due to the furan structure present in the solid matrix of HUs $[23,46]$. It was also observed in the spectra for HUs-Cn4, HUs-Cn5, and HUs-Cn6 a specific peak between 668 and $608 \mathrm{~cm}^{-1}$, resulting from flexion in $\mathrm{C}=\mathrm{O}$.

The absorption at $1420 \mathrm{~cm}^{-1}$ corresponds to the stretch C$\mathrm{O}-\mathrm{C}$ of furanylic ether [48]. Besides the previous one, in these samples, the bands near 1215 and $1170 \mathrm{~cm}^{-1}$ correspond to the phenolic ring or phenolic hydroxide regarding the vibrations of functional groups of residual lignin. It is also important to highlight that the presence of a relevant phenolic structure, which was confirmed by the absorption band at $1204 \mathrm{~cm}^{-1}$, predominant in HUs-Cn1, HUs-Cn2, and HUs-Cn3 [49]. When compared to SCB, the weaker peak between 1168 and $1161 \mathrm{~cm}^{-1}$ corresponds to the stretching of $\mathrm{C}-\mathrm{O}$ in alcohols and aliphatic ethers [49], and the peak near $1450 \mathrm{~cm}^{-1}$ may be attributed to vibrations of deformation $\mathrm{CH}_{2}$ in aliphatic chains present in HUs [23].

Inside the region of the fingerprint, the peaks resulting due to polysaccharides include the peak in $897 \mathrm{~cm}^{-1}$ corresponding to deformation $\mathrm{C}-\mathrm{H}$ [44] that disappears in HUs-Cn1, HUs-Cn2, and HUs-Cn3 (Fig. 6). Besides that, absorptions in 1260,1161 , and $1034 \mathrm{~cm}^{-1}$ were attributed to the stretch of $\mathrm{C}-\mathrm{O}$ of aliphatic alcohols and ethers [47], the stretch of $\mathrm{C}-$ $\mathrm{O}$ in polysaccharides [44], or deformation of the furan ring being characteristic of HUs produced from sugars [45]. The peak in $1117 \mathrm{~cm}^{-1}$ occurs due to the skeletal aromatic stretching of $\mathrm{C}-\mathrm{O}$ of residual lignin [44]. The band near $834 \mathrm{~cm}^{-1}$ corresponds to the aromatic deformation of $\mathrm{C}-\mathrm{H}$. The same observation was made by Rasrendra et al. [47], where it corresponded to the interval between 850 and $700 \mathrm{~cm}^{-1}$.

In general, a comparison between the FTIR spectra of the HUs obtained via the catalytic process with $\mathrm{H}_{2} \mathrm{SO}_{4}$ and the HUs formed through the hydrothermal process suggests that the two sets have different distributions of substituents in their unities of furanyl, phenolic, and hydroxyl. This is due to the difference in the oxidizing strength of the hydrolysis environment. Thus, the HUs obtained in $\mathrm{Cn} 1, \mathrm{Cn} 2$, and $\mathrm{Cn} 3$ are much more oxidized than the HUs obtained in scenarios $\mathrm{Cn} 4, \mathrm{Cn} 5$, and Cn6.

\section{Economic Analysis of Scenarios}

The results of the economic analysis are presented in Table 6 . Considering the LA price for the specialties market, the EBITDA margin of the scenario $\mathrm{Cn} 1, \mathrm{Cn} 2, \mathrm{Cn} 3$, and $\mathrm{Cn} 6$ attains figures of $80-90 \%$ for even low yields of LA (scenario
Table 6 Results of the economic analysis. In scenario Cn4, MSP is unavailable because no LA was produced

\begin{tabular}{lll}
\hline Scenario & EBITDA margin & MSP (\$/t) \\
\hline Cn1 & $91 \%$ & 98 \\
Cn2 & $88 \%$ & 479 \\
Cn3 & $94 \%$ & 236 \\
Cn4 & $29 \%$ & n.a. \\
Cn5 & $30 \%$ & 5379 \\
Cn6 & $81 \%$ & 363 \\
\hline
\end{tabular}

Cn6) because of its high added value. Nevertheless, it should be noted that the LA suitable for applications in the specialties market requires high purity. Hence, the recovery process should include an additional separation step (e.g., crystallization). Moreover, the specialties market for LA is limited in size: about $20 \mathrm{kt} / \mathrm{y}$ in 2020 [28]. This market volume could be supplied by a single state-of-the-art autonomous Brazilian sugarcane mill processing 4 million tons of sugarcane per year using only $28 \%$ of its surplus bagasse [24]. Therefore, this price is not suitable for large-scale production of LA.

Literature reports several other uses for LA outside the specialties market granted that its price is low enough [8]. In this context, the analysis of the MSP for an EBITDA margin of $30 \%$ led to a price of $\$ 98 / t$ in scenario $\mathrm{Cn} 1$ (Table 6), which is compatible with previous price estimates for large-scale LA production [29]. Such low MSP for LA is a result of the biomass fractionation strategy because part of the revenue is also obtained from selling ethanol (fermentation of sugars from PT) and lignin (recovered after DL). This price is low enough to enable the conversion of LA to $\gamma$-valerolactone or dibutyl ketone, both of which can be blended into gasoline or used in the production of other liquid hydrocarbon fuels [25]. Still, to enable production at large-scale, it is necessary to address the challenge of HUs and how to safely use them as supplementary boiler fuel in biomass boilers or to develop new applications for them.

\section{The Challenge of the Current Circular Economy in Valuing HUs}

Besides the already known environmental advantages of products obtained from renewable and/or biodegradable sources, the use of several sources of renewable raw materials (such as SCB for example), as well as the intensive use of their products and by-products (ethanol, sugar, lignin, and others), might help biorefineries in maximizing their profit margins [32]. Therefore, with the desire of having an attractive circular economy, the conversion of SCB into chemical products, materials, and fuels emerges nowadays as a promising alternative for the replacement of fossil resources. In this context, it is fundamental to discuss the possible applications of HUs. 
The diverse range of formation/production of HUs depends upon the catalytic conditions of conversion of the biomass and the source of the substrate or agro-industrial waste. For instance, Weingarten et al. [50] reported a HUs yield of approximately $31.6 \%$ from D-glucose using acid catalysis with $\mathrm{HCl}$ for $2.5 \mathrm{~h}$. Other examples include the conversion of cellulose [51] and fructose [52] having a yield of $49.6 \%$ and $16.0 \%$ respectively. In an alternative approach, using a biphasic system, Ordomsky et al. [53] obtained typical HUs yields during the reaction of dehydration of glucose of almost $50.0 \%$ using $\mathrm{ZrPO}$ in an aqueous medium. Thus, HUs were observed as a residue (or by-products) occurring in reaction systems with acid aqueous media or heterogeneous catalysts, both in water and in organic solvents [54].

The formation of HUs is inevitable during the production of LA. Preliminary investigations are being made and forwarded to the valuation of HUs approaching the structure and its formation mechanism $[14,46]$. Recently, it was demonstrated that HUs generally contained a carbon content of 60-80 wt $\%$ [55], which indicated that more than $30 \%$ of the initial carbon in cellulose was wasted as solid carbonaceous residue. As a material with high carbon content, Kang et al. [55], showed that about $74.4 \%$ of the initial carbon of cellulose was transferred into value-added products, ( $47 \%$ carbon in LA), and also $16.1 \%$ in carbon adsorbents, especially for wastewater treatment. HUs represent a matrix rich in carbon and furanic structures with hydroxyl and carbonyl functional groups. Thus, it has a high potential as a biobased thermoset polymer to be employed in composites applications. Nevertheless, these applications need to be further studied before any added-value applications for HUs are proposed. In the meantime, HUs can be considered as supplementary boiler fuel in the biorefinery, which is suitable for the production of LA which demands a considerable amount of steam [25].

\section{Conclusions}

This investigation evaluated the optimization of the levulinic acid (LA) production process from sugarcane bagasse (SCB). Fractionation of SCB was performed in three steps (acid pretreatment, PT; delignification, DL; and acid-catalyzed conversion, ACC) for the depolymerization of cellulose and conversion to LA. By employing a multi-response optimization strategy, optimized operating conditions were obtained for the third step: $180{ }^{\circ} \mathrm{C}, 7.0 \% \mathrm{w} / \mathrm{v}$ sulfuric acid, $75 \mathrm{~min}$ of reaction, and $12 \%$ of solids loading. In these conditions, the response variables of the study were of $25.1 \pm 1.50 \mathrm{~g} / \mathrm{L}$ for $C_{\mathrm{LA}}, 20.9 \pm$ $1.25 \mathrm{~g} / 100 \mathrm{~g}_{\mathrm{ISF}-\mathrm{D}}$ for $Y_{\mathrm{LA}}$, and $37.5 \pm 2.24 \mathrm{~mol} \%$ for $E_{\mathrm{LA}}$. Based on these optimized conditions, six conversion scenarios were proposed, where it was confirmed the efficiency of the fractionation of biomass in three steps for production of LA in the biorefinery concept. In the three-step fractionation scenario,
LA and formic acid (9.8 and $1.2 \mathrm{~kg}$, respectively per $100 \mathrm{~kg}$ of dry SCB) were obtained allied with the inevitable production of HUs (humins, $13.3 \mathrm{~kg}$, based on $100 \mathrm{~kg}$ of dry SCB). Even though this was not the best LA yield among the studied scenarios, the biomass fractionation strategy of biorefineries allowed for the separation of other added-value components, which allow a smaller minimum selling price for LA, fundamental for many possible market applications. The chemical composition of HUs was analyzed and discussed. Considering the biorefinery concept in which all products and by-products can be used to integrate value to biomass, HUs still represent a challenge because it has a chemical structure that is not yet fitted for many applications besides burning as supplementary boiler fuel in biorefineries. Therefore, other potential uses for HUs can add more value to the LA production chain.

Author Contributions

Emília Savioli Lopes: conceptualization, methodology, validation, formal analysis, data Curation, writing - original draft, visualization; Jean Felipe Leal Silva: conceptualization, methodology, writing - reviewing and editing, visualization; Elmer Ccopa Rivera: writing — original draft, writingreviewing and editing, visualization; Alana Petrina Gomes: visualization, methodology, validation, investigation, writing — original draft; Melina Savioli Lopes: methodology, formal analysis; Rubens Maciel Filho: conceptualization, validation, resources, writing - reviewing and editing, supervision, project administration, funding acquisition; Laura Plazas Tovar: conceptualization, validation, writingoriginal draft, writing - reviewing and editing, resources, visualization, supervision, project administration, funding acquisition.

Funding Information This work was supported by São Paulo Research Foundation-FAPESP (grant numbers 2015/17592-3, 2015/20630-4, 2016/10450-1, and 2017/23335-9) and National Council for Scientific and Technological Development-CNPq (Public investment by Universal Call MCTIC/CNPq no. 28/2018 and grant number 408149/ 2018-3)

\section{References}

1. D'Amato D, Korhonen J, Toppinen A (2019) Circular, green, and bio economy: how do companies in land-use intensive sectors align with sustainability concepts? Ecol Econ 158:116-133

2. Ingle K, Vitkin E, Robin A et al (2018) Macroalgae biorefinery from Kappaphycus alvarezii: conversion modeling and performance prediction for India and Philippines as examples. Bioenergy Res 11:22-32

3. Liu C, Wu S, Zhang H, Xiao R (2019) Catalytic oxidation of lignin to valuable biomass-based platform chemicals: a review. Fuel Process Technol 191:181-201 
4. CONAB (2019) Acompanhamento da Safra Brasileira: Cana-deaçúcar, terceiro levantamento. Companhia Nacional de Abastecimento, Brasília. https://www.conab.gov.br/info-agro/ safras/cana. Accessed 13 Nov 2019

5. Rodriguez RP, Manochio C, Moraes B d S (2019) Energy integration of biogas production in an integrated $1 \mathrm{G} 2 \mathrm{G}$ sugarcane biorefinery: modeling and simulation. Bioenergy Res 12:158 167. https://doi.org/10.1007/s12155-018-9950-z

6. Bevilaqua DB, Rambo MKD, Rizzetti TM et al (2013) Cleaner production: levulinic acid from rice husks. J Clean Prod 47:96101. https://doi.org/10.1016/j.jclepro.2013.01.035

7. Morone A, Apte M, Pandey RA (2015) Levulinic acid production from renewable waste resources: bottlenecks, potential remedies, advancements and applications. Renew Sust Energ Rev 51:548565. https://doi.org/10.1016/j.rser.2015.06.032

8. Leal Silva JF, Grekin R, Mariano AP, Maciel Filho R (2018) Making levulinic acid and ethyl levulinate economically viable: a worldwide technoeconomic and environmental assessment of possible routes. Energy Technol 6:613-639. https://doi.org/10.1002/ ente. 201700594

9. Fitzpatrick S. (1997) U.S. patent 5,608,105 production of levulinic acid from carbohydrate-containing materials

10. Pradipta MSA, Purnamasari NR, Pradana YS (2019) Levulinic acid synthesis from Indonesian sugarcane bagasse using two-step acid catalyzed treatment. AIP Conf Proc 2085:1-8

11. Ji H, Dong C, Yang G, Pang Z (2019) Production of levulinic acid from lignocellulosic biomass with a recyclable aromatic acid and its kinetic study. BioResources 14:725-736

12. Jeong H, Jang S, Hong C, Kim SH, Lee SY, Lee SM, Choi JW, Choi IG (2017) Levulinic acid production by two-step acid-catalyzed treatment of Quercus mongolica using dilute sulfuric acid. Bioresour Technol 225:183-190

13. Liang C, Hu Y, Wang Y et al (2018) Production of levulinic acid from corn cob residue in a fed-batch acid hydrolysis process. Process Biochem 73:124-131

14. Kang S, Fu J, Zhang G (2018) From lignocellulosic biomass to levulinic acid: a review on acid-catalyzed hydrolysis. Renew Sust Energ Rev 94:340-362. https://doi.org/10.1016/J.RSER.2018.06. 016

15. Sluiter A, Ruiz R, Scarlata C, Sluiter J, Templeton D (2008). Determination of extractives in biomass: laboratory analytical procedure (LAP). Technical report NREL/TP-510-42619. National Renewable Energy Laboratory, Golden, Colorado. https://www. nrel.gov/docs/gen/fy08/42619.pdf. Accessed 5 May 2019

16. Sluiter A, Hames B, Ruiz R, Scarlata C, Sluiter J, Templeton D, Crocker D (2012). Determination of structural carbohydrates and lignin in biomass: laboratory analytical procedure (LAP). Technical report NREL/TP-510-42618. National Renewable Energy Laboratory, Golden, Colorado. https://www.nrel.gov/docs/gen/ fy13/42618.pdf. Accessed 5 May 2019

17. Canilha L, Santos VTO, Rocha GJM, Almeida e Silva JB, Giulietti M, Silva SS, Felipe MG, Ferraz A, Milagres AM, Carvalho W (2011) A study on the pretreatment of a sugarcane bagasse sample with dilute sulfuric acid. J Ind Microbiol Biotechnol 38:1467-1475

18. Gouveia ER, Nascimento RT d, Souto-Maior AM, Rocha GJ d M (2009) Validação de metodologia para a caracterização química de bagaço de cana-de-açúcar. Quim Nova 32:1500-1503

19. Sluiter A, Hames B, Ruiz R, Scarlata C, Sluiter J, Templeton D (2008). Determination of sugars, byproducts, and degradation products in liquid fraction process samples: laboratory analytical procedure (LAP). Technical report NREL/TP-510-42623. National Renewable Energy Laboratory, Golden, Colorado. https://www. nrel.gov/docs/gen/fy08/42623.pdf. Accessed 5 May 2019

20. Ramli NAS, Amin NAS (2014) Catalytic hydrolysis of cellulose and oil palm biomass in ionic liquid to reducing sugar for levulinic acid production. Fuel Process Technol 128:490-498. https://doi. org/10.1016/j.fuproc.2014.08.011

21. Raissi S, Farsani R-E (2009) Statistical process optimization through multi-response surface methodology. Int J Math Comput Sci 3:247-251

22. Sunphorka S, Chavasiri W, Oshima Y, Ngamprasertsith S (2012) Protein and sugar extraction from rice bran and de-oiled rice bran using subcritical water in a semi-continuous reactor: optimization by response surface methodology. Int J Food Eng 8(3):26. https:// doi.org/10.1515/1556-3758.2262

23. Hoang TMC, Van Eck ERH, Bula WP et al (2015) Humin based by-products from biomass processing as a potential carbonaceous source for synthesis gas production. Green Chem 17:959-972

24. Dias MOS, Junqueira TL, Cavalett $O$ et al (2012) Integrated versus stand-alone second generation ethanol production from sugarcane bagasse and trash. Bioresour Technol 103:152-161. https://doi.org/ 10.1016/j.biortech.2011.09.120

25. Leal Silva JF (2018) Process development for sugarcane conversion to ethyl levulinate: a route for a viable biodiesel additive. Dissertation, University of Campinas

26. Leal Silva JF, Mariano AP, Maciel Filho R (2018) Economic potential of 2-methyltetrahydrofuran (MTHF) and ethyl levulinate (EL) produced from hemicelluloses-derived furfural. Biomass Bioenergy 119:492-502. https://doi.org/10.1016/j.biombioe.2018. 10.008

27. Ludmila H, Michal J, Andrea Š, Aleš H (2015) Lignin, potential products and their market value. Wood Res 60:973-986

28. 360 Market Updates (2020) Global levulinic acid market research report 2020. Pune

29. Hayes DJ, Fitzpatrick S, Hayes MHB, Ross JRH (2008) The biofine process - production of levulinic acid, furfural, and formic acid from lignocellulosic feedstocks. In: Biorefineries-industrial processes and products: status quo and future directions. WileyVCH Verlag GmbH, Weinheim, pp 139-164

30. Dussan K, Girisuta B, Haverty D, Leahy JJ, Hayes MH (2013) Kinetics of levulinic acid and furfural production from Miscanthus $\times$ giganteus. Bioresour Technol 149:216-224. https:// doi.org/10.1016/j.biortech.2013.09.006

31. Raspolli Galletti AM, Antonetti C, De Luise V et al (2012) Levulinic acid production from waste biomass. BioResources 7: 1824-1835. https://doi.org/10.15376/biores.7.2.1824-1835

32. Fleig OP, Lopes ES, Rivera EC et al (2018) Concept of rice husk biorefining for levulinic acid production integrating three steps: multi-response optimization, new perceptions and limitations. Process Biochem 65:146-156

33. Kim HS, Kim SK, Jeong GT (2018) Catalytic conversion of glucose into levulinic and formic acids using aqueous Brønsted acid. J Ind Eng Chem 63:48-56

34. Jeong GT (2014) Production of levulinic acid from glucosamine by dilute-acid catalyzed hydrothermal process. Ind Crop Prod 62:7783

35. Kang M, Kim SW, Kim J-W et al (2013) Optimization of levulinic acid production from Gelidium amansii. Renew Energy 54:173179. https://doi.org/10.1016/j.renene.2012.08.028

36. Ramli NAS, Amin NAS (2017) Optimization of biomass conversion to levulinic acid in acidic ionic liquid and upgrading of levulinic acid to ethyl levulinate. Bioenergy Res 10:50-63

37. Muñoz T, Rache LY, Rojas HA, Romanelli GP, Martinez JJ, Luque R (2020) Production of 5-hydroxymethyl-2-furan carboxylic acid by Serratia marcescens from crude 5-hydroxymethylfurfural. Biochem Eng J 154:107421. https://doi.org/10.1016/j.bej.2019. 107421

38. Park MR, Kim SK, Jeong GT (2018) Optimization of the levulinic acid production from the red macroalga, Gracilaria verrucosa using methanesulfonic acid. Algal Res 31:116-121 
39. Fang Q, Hanna MA (2002) Experimental studies for levulinic acid production from whole kernel grain sorghum. Bioresour Technol 81:187-192. https://doi.org/10.1016/S0960-8524(01)00144-4

40. Wang X, Zhang C, Lin Q et al (2018) Solid acid-induced hydrothermal treatment of bagasse for production of furfural and levulinic acid by a two-step process. Ind Crop Prod 123:118-127

41. Chamnankid B, Ratanatawanate C, Faungnawakij K (2014) Conversion of xylose to levulinic acid over modified acid functions of alkaline-treated zeolite Y in hot-compressed water. Chem Eng J 258:341-347. https://doi.org/10.1016/j.cej.2014.07.036

42. Jeong H, Park SY, Ryu GH et al (2018) Catalytic conversion of hemicellulosic sugars derived from biomass to levulinic acid. Catal Commun 117:19-25

43. Zeitsch KJ (2000) The chemistry and technology of furfural and its many by-products. Elsevier, Amsterdam

44. Acquah GE, Via BK, Fasina OO, Eckhardt LG (2016) Rapid quantitative analysis of forest biomass using Fourier transform infrared spectroscopy and partial least squares regression. J Anal Methods Chem 2016:1-10

45. van Zandvoort I, Wang Y, Rasrendra CB, van Eck E, Bruijnincx PC, Heeres HJ, Weckhuysen BM (2013) Formation, molecular structure, and morphology of Humins in biomass conversion: influence of feedstock and processing conditions. ChemSusChem 6: 1745-1758. https://doi.org/10.1002/cssc.201300332

46. Van Zandvoort I, Koers EJ, Weingarth M et al (2015) Structural characterization of 13C-enriched humins and alkali-treated 13C humins by 2D solid-state NMR. Green Chem 17:4383-4392. https://doi.org/10.1039/c5gc00327j

47. Rasrendra CB, Windt M, Wang Y et al (2013) Journal of analytical and applied pyrolysis experimental studies on the pyrolysis of humins from the acid-catalysed dehydration of C6-sugars. J Anal Appl Pyrolysis 104:299-307. https://doi.org/10.1016/j.jaap.2013. 07.003
48. Liang J, Chen X, Wang L et al (2016) Hydrolysis behaviors of sugarcane bagasse pith in subcritical carbon dioxide-water. RSC Adv 6:99322-99330

49. Ma Z, Chen D, Gu J et al (2015) Determination of pyrolysis characteristics and kinetics of palm kernel shell using TGA-FTIR and model-free integral methods. Energy Convers Manag 89:251-259

50. Weingarten R, Cho J, Xing R et al (2012) Kinetics and reaction engineering of Levulinic acid production from aqueous glucose solutions. ChemSusChem 5:1280-1290. https://doi.org/10.1002/ cssc.201100717

51. Weingarten R, Conner WC, Huber GW (2012) Production of levulinic acid from cellulose by hydrothermal decomposition combined with aqueous phase dehydration with a solid acid catalyst. Energy Environ Sci 5:7559-7574

52. Hu X, Wu L, Wang Y, Song Y, Mourant D, Gunawan R, Gholizadeh M, Li CZ (2013) Acid-catalyzed conversion of mono- and poly-sugars into platform chemicals: effects of molecular structure of sugar substrate. Bioresour Technol 133:469-474

53. Ordomsky VV, Sushkevich VL, Schouten JC et al (2013) Glucose dehydration to 5-hydroxymethylfurfural over phosphate catalysts. J Catal 300:37-46

54. Filiciotto L, Balu AM, Van der Waal JC, Luque R (2018) Catalytic insights into the production of biomass-derived side products methyl levulinate, furfural and humins. Catal Today 302:2-15

55. Kang S, Pan J, Gu G et al (2018) Sequential production of levulinic acid and porous carbon material from cellulose. Materials (Basel) 11:1-15. https://doi.org/10.3390/ma11081408

Publisher's Note Springer Nature remains neutral with regard to jurisdictional claims in published maps and institutional affiliations. 